\title{
Synthesis and Characterization of Mannosylated Formulations to Deliver a Minicircle DNA Vaccine
}

\author{
Ana Sofia Serra ${ }^{1}$, Dalinda Eusébio ${ }^{1}$, Ana Raquel Neves ${ }^{1}$, Tânia Albuquerque ${ }^{1}$, Himanshu Bhatt ${ }^{2}$, \\ Swati Biswas ${ }^{2}$, Diana Costa ${ }^{1, *}$ and Ângela Sousa ${ }^{1, *}$
}

1 CICS-UBI—Health Sciences Research Centre, Universidade da Beira Interior, Avenida Infante D. Henrique, 6200-506 Covilhã, Portugal; anasofiamms@gmail.com (A.S.S.); dalinda-21@hotmail.com (D.E.); ana_raquel_bastos_neves@hotmail.com (A.R.N.); t_albuquerque@live.com.pt (T.A.)

2 Department of Pharmacy, Nanomedicine Research Laboratory, Birla Institute of Technology \& Science-Pilani, Hyderabad Campus, Jawahar Nagar, Medchal, Hyderabad, Telangana 500078, India; bhattrx@yahoo.com (H.B.); swati.biswas@hyderabad.bits-pilani.ac.in (S.B.)

* Correspondence: dcosta@fcsaude.ubi.pt (D.C.); angela@fcsaude.ubi.pt (Â.S.); Tel.: +351-275-329-002 (D.C. \& Â.S.)

check for updates

Citation: Serra, A.S.; Eusébio, D.; Neves, A.R.; Albuquerque, T.; Bhatt, H.; Biswas, S.; Costa, D.; Sousa, Â. Synthesis and Characterization of Mannosylated Formulations to Deliver a Minicircle DNA Vaccine. Pharmaceutics 2021, 13, 673.

https://doi.org/10.3390/

pharmaceutics 13050673

Academic Editor: Satoshi Uchida

Received: 7 April 2021

Accepted: 4 May 2021

Published: 7 May 2021

Publisher's Note: MDPI stays neutral with regard to jurisdictional claims in published maps and institutional affiliations.

Copyright: (c) 2021 by the authors. Licensee MDPI, Basel, Switzerland. This article is an open access article distributed under the terms and conditions of the Creative Commons Attribution (CC BY) license (https:/ / creativecommons.org/licenses/by/ $4.0 /)$.

\begin{abstract}
DNA vaccines still represent an emergent area of research, giving rise to continuous progress towards several biomedicine demands. The formulation of delivery systems to specifically target mannose receptors, which are overexpressed on antigen presenting cells (APCs), is considered a suitable strategy to improve the DNA vaccine immunogenicity. The present study developed binary and ternary carriers, based on polyethylenimine (PEI), octa-arginine peptide (R8), and mannose ligands, to specifically deliver a minicircle DNA (mcDNA) vaccine to APCs. Systems were prepared at various nitrogen to phosphate group $(\mathrm{N} / \mathrm{P})$ ratios and characterized in terms of their morphology, size, surface charge, and complexation capacity. In vitro studies were conducted to assess the biocompatibility, cell internalization ability, and gene expression of formulated carriers. The high charge density and condensing capacity of both PEI and R8 enhance the interaction with the mcDNA, leading to the formation of smaller particles. The addition of PEI polymer to the R8-mannose/mcDNA binary system reduces the size and increases the zeta potential and system stability. Confocal microscopy studies confirmed intracellular localization of targeting systems, resulting in sustained mcDNA uptake. Furthermore, the efficiency of in vitro transfection can be influenced by the presence of R8-mannose, with great implications for gene expression. R8-mannose/PEI/mcDNA ternary systems can be considered valuable tools to instigate further research, aiming for advances in the DNA vaccine field.
\end{abstract}

Keywords: HPV infection; mannose ligands; minicircle DNA vaccine; polyethyleneimine; R8 peptide

\section{Introduction}

Cancer is a disease that continues to proliferate worldwide and is a major cause of mortality, however the probability of finding a cure is increasing. Cervical cancer is the most relevant disease associated with human papillomavirus (HPV) infection, especially when it is not detected early, evolving to invasive forms [1]. The overexpression of HPV E6 and E7 oncoproteins interferes with cell cycle regulation and proliferation through the impairment of p53 and pRb tumor suppressor proteins, respectively [2]. Although prophylactic HPV vaccination is currently the best strategy for preventing cervical cancer, this type of vaccine induces only humoral immunity (producing neutralizing antibodies) to prevent future infections, however it is not effective in treating pre-existing infections. To fill this gap, several types of therapeutic vaccines against HPV are being studied [3]. In this context, DNA vaccines have particular importance due to their ability to generate cellular and humoral immune responses, based on the use of genetic material sequences from the pathogen that is intended to be fought [4]. Among the different DNA vaccines, 
minicircle DNA (mcDNA) is an innovative and promising DNA molecule. The absence of prokaryotic sequences on the mcDNA overcome some key limitations of the traditional plasmid DNA [5]. E6 and E7 viral oncoproteins are suitable targets for the formulation of therapeutic vaccines, since they are overexpressed in HPV-infected cells at early stages [1].

The success of DNA vaccines is strongly dependent on the development of convenient and efficient gene delivery systems. They should be able to condense and protect the DNA, binding to the membrane and internalizing in eukaryotic cells, overcoming all intracellular and extracellular obstacles [6]. The intracellular delivery of nucleic acids is thought to result from the electrostatic interactions between the positive charges of the delivery system and the negative charges of the cellular membrane. Higher surface charges mean stronger DNA loading capability, which favors effective cell uptake and gene transfection [7]. Viral vectors offer high transfection efficiency for eukaryotic cells. However, they present significant disadvantages, such as antigenicity, potential oncogenic effects, possible virus recombination, or difficulty for large-scale production and storage. To overcome these limitations, several attempts have been made to develop non-viral gene delivery systems based on liposomes, synthetic or natural cationic polymers, and cell-penetrating peptides (CPPs), among others [8].

Among non-viral delivery methods, cell-penetrating peptides (CPPs) have received particular attention due to their ability to enter cells in a non-invasive manner, maintaining the integrity of cell membranes, and they are considered highly efficient and safe [9]. These peptides are generally short at up to 30 amino acids and can be separated into two main groups: arginine-rich and amphipathic peptides [10]. Although the delivery properties of CPPs are not questionable, the mechanism of cell uptake and endosomal escape is still controversial [10]. Different studies are currently underway to better understand this mechanism. For instance, the translocation efficiency and cell localization of several arginine-rich peptides with various chain lengths have been analyzed. In particular, the octa-arginine (R8) peptide has shown very satisfactory results in terms of cell internalization and nucleus accumulation [11-15]. In addition, CPPs can also be used to enhance nanosystem activity and biocompatibility [16].

Cationic polymers have been extensively studied due to their ability to condense DNA into polyplexes and facilitate gene delivery $[8,17,18]$. Polyethylenimine (PEI) is the most used synthetic cationic polymer, existing in various molecular weights and linear or branch structures. For instance, branched PEI with higher molecular weights shows greater ability to condense nucleic acids than linear PEI [19]. The abundance of polyamines favors the formulation of PEI/DNA nanocarriers with high surface charge, which improves the transfection efficiency but also increases the toxicity. On the other hand, PEI-based DNA carriers with low-molecular-weight are non-toxic but exhibit low transfection efficiency. As such, PEI conjugation with other molecules is a possible approach to reduce toxicity [7].

Antigens encoded in DNA vaccines need to be processed by antigen-presenting cells (APCs) to activate both humoral and cellular immune responses [20]. To increase the efficiency of DNA vaccines in terms of immunogenicity, several strategies have focused on targeting APCs [21]. Dendritic cells (DCs) and macrophages represent the crucial APCs for efficient activation of T-cells and B-cells and are concentrated in areas of potential antigen entry, especially around the epithelial and mucous surfaces [22]. Therefore, the development of new and improved formulations containing specific ligands to target and deliver DNA vaccines into APCs has been explored [21]. Mannose ligands are often used to bind mannose receptors that are highly expressed on surfaces of DC and macrophages. Some studies have evidenced the entrance of mannosylated formulations into Raw 264.7 cells through receptor-mediated endocytosis $[23,24]$. In addition, the three-dimensional conformation and multimerization pattern of each mannose receptor determine its ability to recognize multiple ligands and regulate immune responses [25].

In this work, binary and ternary delivery systems based on R8 peptide functionalized with mannose ligands with and without the PEI polymer were designed to specifically deliver the mcDNA vaccine to macrophages. R8-mannose/mcDNA and R8-mannose/PEI/ 
mcDNA formulations were explored, optimized, and characterized in terms of their surface morphology, size, surface charge, complexation capacity, and stability. Transfection studies were conducted to assess the biocompatibility, cell internalization, and expression of the genes encoded by the mcDNA vaccine carried by the developed systems. The presented report provides relevant data on the conception, characterization, and transfection efficiency of non-viral delivery systems and is a great contribution to progress in DNA vaccines.

\section{Materials and Methods}

\subsection{Materials}

$\alpha$-D-Mannopyranosylphenyl isothiocyanate (MPITC) and commercial branched PEI with average Mw $25 \mathrm{kDa}$ and GRS Taq DNA polymerase were purchased from Sigma Aldrich Chemicals (St. Louis, MO, USA). R8 peptide was custom synthesized from GCC Biotech Pvt. Ltd. (West Bengal, India). The TripleXtractor used in RNA extraction was obtained from GRISP (Porto, Portugal). DMEM-F12 and DMEM-HG were purchased from GIBCO (Waltham, MA, USA). Sodium bicarbonate was obtained from MP Biomedicals (Santa Ana, CA, USA). DAPI was obtained from Invitrogen (Carlsbad, CA, USA). FITC was obtained from Alfa Aesar (Lanchashire, UK). Agarose and GreenSafe were obtained from NZYtech (Lisbon, Portugal).

\subsection{Methods}

\subsubsection{Amplification and Purification of mcDNA Vector}

To eradicate the oncogenic potential of HPV E7, the HPV E7 gene was modified by NZYTech (Lisbon, Portugal) to include three point mutations preventing the interaction with pRB but maintaining the normal structure of the E7 protein (more information in Figure S1 of the Supplementary Materials). The mutated E7 gene was cloned into the pMC.CMV-MCS-EF1-GFP-SV40PolyA parental plasmid (PP) vector (next to CMV7 promoter), which was amplified in the ZYCY10P3S2T Escherichia coli host strain following production under the induction conditions described by our research group [26]. Briefly, the bacterial cultures were performed in $1 \mathrm{~L}$ Erlenmeyer flasks containing $250 \mathrm{~mL}$ of Terrific Broth medium (20 g/L of tryptone; $24 \mathrm{~g} / \mathrm{L}$ of yeast extract; $4 \mathrm{~mL} / \mathrm{L}$ of glycerol; $0.017 \mathrm{M}$ $\mathrm{KH}_{2} \mathrm{PO}_{4}$, and $0.072 \mathrm{M} \mathrm{K}_{2} \mathrm{HPO}_{4}, \mathrm{pH} 7.0$ ) in an orbital shaker at $42{ }^{\circ} \mathrm{C}$ and $250 \mathrm{rpm}$. For the mcDNA-E7 vector production from its PP precursor, an induction mix containing L-arabinose $0.01 \%(w / v)$ was added. The recombination process was carried out for $2 \mathrm{~h}$ at $32{ }^{\circ} \mathrm{C}$. When induction was completed, cells were recovered by centrifugation and stored at $-20^{\circ} \mathrm{C}$. To obtain the mcDNA-E7 vector, a modified alkaline lysis method was performed as described by Diogo et al. [27]. To isolate the mcDNA vector, resulting supernatants were loaded directly onto a Sephacryl SF-1000 instrument, as previously described by our research group [28]. An AKTA Pure system (GE Healthcare, Buckinghamshire, UK) with UNICORNTM 6.3 software (GE Healthcare, Buckinghamshire, UK) was used to perform all chromatographic runs. The resultant chromatographic fractions were desalted and concentrated using Vivaspin ${ }^{\circledR} 6$ centrifugal concentrators (Vivaproducts, Littleton, MA, USA) and analyzed by agarose gel electrophoresis.

\subsubsection{Agarose Gel Electrophoresis}

The $0.8 \%$ or $1 \%(w / v)$ agarose gel $(0.4 \mathrm{~g}$ or $0.5 \mathrm{~g}$ of agarose) was prepared for 50 $\mathrm{mL}$ of $1 \times$ TAE buffer ( $40 \mathrm{mM}$ Tris base, $20 \mathrm{mM}$ acetic acid, $1 \mathrm{mM}$ EDTA at $\mathrm{pH}$ 8.0) and stained with $0.6 \mu \mathrm{L}$ of GreenSafe. Electrophoresis was performed for $40 \mathrm{~min}$ at $120 \mathrm{~V}$ and the gel was analyzed using ultraviolet (UV) light through the Uvitec Fire-Reader system (UVITEC, UK).

\subsubsection{Synthesis of $\alpha$-D-Mannopyranosylphenyl Isothiocyanate-Octa-Arginine Conjugate}

Mannose was conjugated to R8 via the reaction between isothiocyanate and the amine groups (Figure 1). Briefly, $\alpha$-D-mannopyranosylphenyl isothiocyanate (MPITC) was dissolved in methanol and added dropwise into the methanolic solution of R8 at the 
MPITC/R8 mole ratio of 1.2:1 under stirring for $24 \mathrm{~h}$. The methanol was evaporated under vacuum using a rotary evaporator.

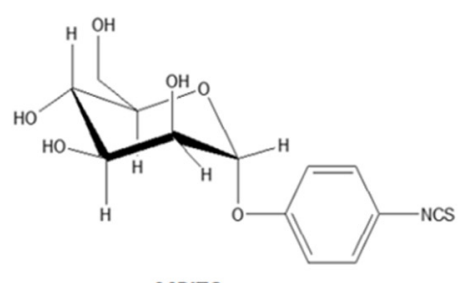

MPITC

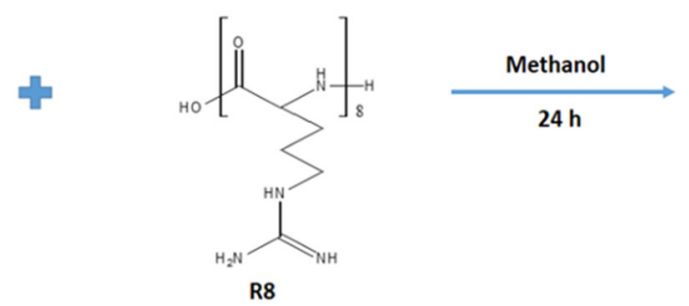

R8

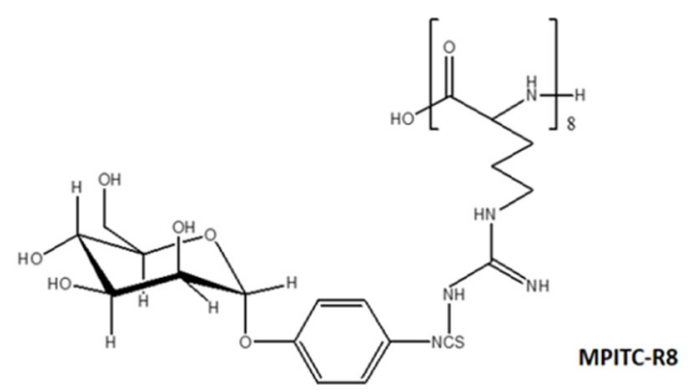

Figure 1. Synthesis scheme of MPITC-R8 conjugate.

\subsubsection{Characterization of Synthesized MPITC-R8 Conjugate}

The characterization of the synthesized MPITC-R8 conjugate was obtained using $1 \mathrm{H}$ NMR of the synthesized conjugate and size exclusion chromatography (SEC). 1H NMR was performed by dissolving the compound $(10 \mathrm{mg})$ in deuterated methanol (CD3OD) $(1 \mathrm{~mL})$ using a Bruker spectrometer (300 MHz, Bruker, Billerica, MA, USA) operating at 300 mega $\mathrm{Hz}$ at $25^{\circ} \mathrm{C}$. The SEC was performed to estimate the molecular weight of the synthesized MPITC-R8 conjugate. The samples were eluted through an Ultrahydrogel ${ }^{\mathrm{TM}}$ linear SEC column $(7.8 \mathrm{~mm} \times 300 \mathrm{~mm})$ in a gel permeation chromatography (GPC) system (Waters Corporation, St. Louis, MO, USA). Milli-Q water was used as a mobile phase with a flow rate of $0.7 \mathrm{~mL} / \mathrm{min}$. The SEC standards were run before analyzing the conjugates.

\subsubsection{Preparation of R8-Mannose/mcDNA and R8-Mannose/PEI/mcDNA Complexes}

R8-mannose lyophilized powder was suspended in ultrapure water and aliquots of $0.5 \mathrm{mg} / \mathrm{mL}$ were prepared. PEI stock solutions were prepared in sodium acetate buffer ( $0.1 \mathrm{mM}$ sodium acetate/0.1 M acetic acid, $\mathrm{pH} 4.5)$. R8-mannose/mcDNA-E7 binary and R8-mannose/PEI/mcDNA-E7 ternary systems were prepared, characterized, and evaluated to determine their potential as delivery systems. Formulation of R8mannose/mcDNA-E7 binary particles was achieved by adding variable concentrations of peptide solution to a fixed amount of mcDNA $(1 \mu \mathrm{g})$ under vortexing for $1 \mathrm{~min}$. To formulate R8-manose/PEI/mcDNA-E7 ternary systems, different amounts of PEI were added to a fixed volume of mcDNA and then variable concentrations of R8-mannose were added to PEI/mcDNA-E7 particles under vortexing for $1 \mathrm{~min}$. All systems were left for $30 \mathrm{~min}$ at room temperature to allow particle formation and then centrifuged at 10,000 rpm for $20 \mathrm{~min}$ at $4{ }^{\circ} \mathrm{C}$.

Both systems were prepared at various $\mathrm{N} / \mathrm{P}$ ratios, considering the molar ratio of positively charged amine groups from R8 and PEI $(\mathrm{N})$ to negatively charged phosphates in the DNA backbone $(\mathrm{P})$. The electrophoretic mobility of the supernatants from all nanoparticle formulations was evaluated by agarose gel electrophoresis of $1 \%$ to ensure the entire mcDNA amount was complexed (Figure S2). 


\subsubsection{Characterization of Systems}

Fourier transform infrared spectroscopy (FTIR) was applied to investigate the functional groups on the particle surfaces. The pellet recovered from different formulations was suspended in $10 \mu \mathrm{L}$ of ultrapure water. The spectra were acquired using a Nicolet iS10 FTIR spectrophotometer (Thermo Scientific, Waltham, MA, USA) with an average of 120 scans, a spectral width ranging from 4000 and $600 \mathrm{~cm}^{-1}$, and a spectral resolution of $32 \mathrm{~cm}^{-1}$. The spectra of isolated R8 and mcDNA samples were acquired for comparative analysis.

Scanning electron microscopy (SEM) was used to obtain information concerning the morphology of both systems. Different formulations were centrifuged and the pellet was recovered and suspended in an aqueous solution containing $40 \mu \mathrm{L}$ of tungsten. The solution was placed in a round-shaped cover slip and dried overnight at room temperature. The samples were sputter-coated with gold using an Emitech K550 (London, England) sputter coater. A Hitachi S-2700 (Tokyo, Japan) scanning electron microscope with an accelerating voltage of $20 \mathrm{kV}$ at various magnifications was used to analyze the morphologies of binary and ternary systems.

The average size and zeta potential of the particles were determined via dynamic light scattering (DLS) at $25^{\circ} \mathrm{C}$ using a Zetasizer nano ZS device (Malvern Instruments, Worcestershire, UK). DLS techniques were performed with a He-Ne laser at $633 \mathrm{~nm}$ with non-invasive backscatter (NIBS) to assess systems size and with electrophoretic light scattering optics using a M3-PALS laser (phase analysis light Scattering) for charge characterization. All experiments were performed in triplicate and were analyzed using Malvern zetasizer software v 6.34 (Malvern Instruments, Worcestershire, UK). The pellet containing the particles was suspended in $5 \%$ glucose with $1 \mathrm{mM} \mathrm{NaCl}$.

\subsubsection{Stability Assays}

R8-mannose/mcDNA-E7 and R8-mannose/PEI/mcDNA-E7 systems were incubated for different time periods $(0,1$, and $4 \mathrm{~h})$ with $25 \mu \mathrm{L}$ of DMEM medium supplemented with $10 \% \mathrm{FBS}$ and $25 \mu \mathrm{L}$ of trypsin solution at $37^{\circ} \mathrm{C}$. The release and mcDNA degradation were monitored by $1 \%$ agarose gel electrophoresis.

\subsubsection{In Vitro Transfection}

Cell culture experiments were performed using human fibroblast cells (ATCC ${ }^{\circledR}$ PCS201-012 ${ }^{\mathrm{TM}}$ ) and Raw 264.7 cells (murine macrophage cells, ATCC ${ }^{\circledR}$ TIB-71 ${ }^{\mathrm{TM}}$ ). Human fibroblast cells were grown with Dulbecco's modified Eagle's medium with Ham's F-12 Nutrient Mixture (DMEM-F12) supplemented with 10\% heat-inactivated fetal bovine serum, $2.438 \mathrm{~g} / \mathrm{L}$ sodium bicarbonate, and $1 \%(v / v)$ of a mixture of antibiotics composed of penicillin $(100 \mu \mathrm{g} / \mathrm{mL})$ and streptomycin $(100 \mu \mathrm{g} / \mathrm{mL})$. Raw 264.7 cells were grown with Dulbecco's modified Eagle's medium with High Glucose (DMEM-HG) supplemented with $10 \%$ non-inactivated fetal bovine serum, $1.5 \mathrm{~g} / \mathrm{L}$ sodium bicarbonate, and with $1 \%(v / v)$ of a mixture of antibiotics composed of penicillin $(100 \mu \mathrm{g} / \mathrm{mL})$ and streptomycin $(100 \mu \mathrm{g} / \mathrm{mL})$. The cellular growth was promoted at $37^{\circ} \mathrm{C}$ in a humidified atmosphere containing $5 \%$ $\mathrm{CO}_{2}$. For transfection studies, human fibroblast cells and Raw 264.7 cells were seeded in 12-well plates at densities of $2.5 \times 10^{5}$ cells/well and $2 \times 10^{5}$ cells/well, respectively, in $1 \mathrm{~mL}$ complete medium. After $24 \mathrm{~h}$ and before transfection occurred, the medium was replaced by a medium without FBS and antibiotic supplementation (incomplete medium) in order to promote transfection. At confluency $(50-60 \%)$, the medium was removed and the cells were transfected with different particles dissolved in incomplete medium. For human fibroblast transfection, $7.5 \mu \mathrm{g}$ of encapsulated mcDNA from each system was added per well. Raw 264.7 cells were transfected by adding $6 \mu \mathrm{g}$ of encapsulated mcDNA from each system per well. After $6 \mathrm{~h}$ of transfection, the incomplete medium was replaced by complete medium. 


\subsubsection{Biocompatibility Study}

A resazurin assay was used in order to evaluate the systems' biocompatibility. Human fibroblasts and Raw 264.7 cells were seeded in 96-well plates at densities of $1 \times 10^{4}$ cells / well and $0.8 \times 10^{4}$ cells/well, respectively. For human fibroblasts, $0.3 \mu \mathrm{g}$ of encapsulated mcDNA from each system was added per well. Raw 264.7 cells were transfected by adding $0.24 \mu \mathrm{g}$ of encapsulated mcDNA from each system per well. After 24 and $48 \mathrm{~h}$ of transfection, the culture medium was discarded and $100 \mu \mathrm{L}$ of fresh complete medium and $20 \mu \mathrm{L}$ of resazurin $0.1 \%(w / v)$ were added to each well and incubated over four hours in the dark at $37^{\circ} \mathrm{C}$ in a humidified atmosphere of $5 \% \mathrm{CO}_{2}$. After incubation, the fluorescence was measured in a spectrofluorometer (SpectraMAX ${ }^{\circledR}$ GeminiTM EM, Molecular Devices, San Jose, CA, USA) at an excitation wavelength of $544 \mathrm{~nm}$ and emission wavelength of $590 \mathrm{~nm}$ to analyze the resorufin fluorescence produced.

\subsubsection{FITC Plasmid Labeling}

Minicircle DNA was stained with FITC by assembling $16.3 \mu \mathrm{L}$ of mcDNA, $2 \mu \mathrm{L}$ of FITC, and $66.7 \mu \mathrm{L}$ of labeling buffer. Samples were placed under constant stirring at room temperature for $4 \mathrm{~h}$ and protected from light. One volume of $3 \mathrm{M} \mathrm{NaCl}(85 \mu \mathrm{L})$ and 2.5 volumes of $100 \%$ ethanol $(212.5 \mu \mathrm{L})$ were added. Samples with stained mcDNA were incubated at $-20^{\circ} \mathrm{C}$ overnight. Subsequently, samples were centrifuged at $4{ }^{\circ} \mathrm{C}$ for $30 \mathrm{~min}$ and the pellet was washed with $75 \%$ ethanol.

\subsubsection{Cellular Uptake and Internalization}

Confocal fluorescence microscopy was used to investigate the cellular uptake and internalization of carriers. Raw 264.7 cells were grown in an 8-well $\mu$-slide (Ibidi, Martinsried, Germany) until $50-60 \%$ confluence was achieved. Nuclei were stained by incubating the cells with DAPI. FITC-labeled mcDNA was encapsulated into R8-mannose/PEI particles and real live transfection was visualized using an LSM 710 confocal laser scanning microscope (Carl Zeiss, Oberkochen, Germany) under $63 \times$ magnification and analyzed with the Zeiss LSM 710 laser scanning confocal microscope (Carl Zeiss SMT, Inc., Oberkochen, Germany). During the experiment, Raw 264.7 cells were maintained at $37^{\circ} \mathrm{C}$ with $5 \% \mathrm{CO}_{2}$.

\subsubsection{Reverse Transcription Polymerase Chain Reaction (RT-PCR)}

RT-PCR was used to detect the E7 mRNA transcripts resulting from the E7 gene transcription encoded in the PEI/mcDNA and R8-mannose/PEI/mcDNA system vector. After $24 \mathrm{~h}$ of transfection, cells were lysed through the addition of TripleXtractor and incubated at room temperature for $5 \mathrm{~min}$. Subsequently, $50 \mu \mathrm{L}$ of chloroform was added and stirred to allow the separation of different biomolecules in different phases, then incubated at room temperature for $10 \mathrm{~min}$. Samples were then centrifuged at 12,000 $\times g$ for $15 \mathrm{~min}$ at $4{ }^{\circ} \mathrm{C}$ to obtain the separation of the aqueous phase containing RNA and the interphase and lower organic phase containing DNA and proteins. The aqueous phase was carefully recovered and $125 \mu \mathrm{L}$ of ice-cold isopropanol was added to precipitate the RNA. Samples were centrifuged again at $12,000 \times \mathrm{g}$ for $15 \mathrm{~min}$ at $4{ }^{\circ} \mathrm{C}$ and the pellet was washed in DEPC water with $125 \mu \mathrm{L}$ of $75 \%$ ethanol to eliminate organic compounds. A new centrifugation was carried out at $12,000 \times g$ for $5 \mathrm{~min}$ at $4{ }^{\circ} \mathrm{C}$ and the RNA pellet was resuspended in $20 \mu \mathrm{L}$ of DEPC. To confirm the success of RNA extraction, electrophoresis was performed on $1 \%$ agarose gel and the samples were quantified on a NanoPhotometer ${ }^{\mathrm{TM}}$. The cDNA synthesis was performed by using Xpert cDNA Synthesis (GRiSP-Research Solutions, Porto, Portugal), following the manufacturer's protocol. PCR amplification was performed by adding in each PCR reaction $8.25 \mu \mathrm{L}$ of RNase-free water, $0.40 \mu \mathrm{L}$ of forward primer ( $5^{\prime}$-AAT CTA GAA TGC CTG ATA CAC CTA C $\left.-3^{\prime}\right)$ and reverse primer ( $5^{\prime}$-ATG GAT CCT TAT GGT TTC TGA GAA CAG A - $3^{\prime}$ ), $0.7 \mu \mathrm{L}$ of $\mathrm{MgCl} 2,0.25 \mu \mathrm{L}$ of dNTPs, 1.25 $\mu \mathrm{L}$ of PCR buffer, $0.25 \mu \mathrm{L}$ of GRS Taq, and $1 \mu \mathrm{L}$ of cDNA. The samples were homogenized and a mini-spin was performed. Samples were then placed in a $1100^{\mathrm{TM}}$ Thermal Cycler (Bio-Rad Laboratories, Inc, Hercules, California, USA) with the following sequence: $95{ }^{\circ} \mathrm{C}$ 
for $5 \mathrm{~min}, 26$ cycles of $30 \mathrm{~s}$ at $95^{\circ} \mathrm{C}, 30 \mathrm{~s}$ at $60^{\circ} \mathrm{C}, 1 \mathrm{~min}$ at $72{ }^{\circ} \mathrm{C}$, and finally $10 \mathrm{~min}$ at $72{ }^{\circ} \mathrm{C}$. PCR products were analyzed by electrophoresis on an agarose gel and were visualized in a UVItec Gel documentation system under UV light (UVItec Limited, Cambridge, UK).

\subsubsection{Reverse Transcription Quantitative Real-Time PCR (RT-qPCR)}

To quantitatively analyze the levels of transcripts, RT-qPCR was performed. The mix for a reaction with primers designed for the transcript of the E7 gene was prepared with $10 \mu \mathrm{L}$ of SYBR TM Green Master Mix, $0.64 \mu \mathrm{L}$ FW primer, $0.64 \mu \mathrm{L}$ RV primer, $7.72 \mu \mathrm{L}$ of sterile $\mathrm{H}_{2} \mathrm{O}$, and $1 \mu \mathrm{L}$ of $\mathrm{cDNA}$, resulting in a volume of $20 \mu \mathrm{L}$ per reaction. The mix for reaction with the primer pair of the GAPDH housekeeping gene transcript (FW: $5^{\prime}$ - ATG GGG AAG GTG AAG GTC G -3'; RV: 5’- GGG GTC ATT GAT GGC AAC AAT A -3') was prepared with $10 \mu \mathrm{L}$ of NZY qPCR Green Master Mix (2x), 1.2 $\mu \mathrm{L}$ FW primer, $1.2 \mu \mathrm{L}$ RV primer, $7.5 \mu \mathrm{L}$ of sterile $\mathrm{H}_{2} \mathrm{O}$, and $1 \mu \mathrm{L}$ of cDNA, resulting in a volume of $20 \mu \mathrm{L}$. The reaction mixtures were placed in a Real-Time CFX ConnectTM system (BioRad, Hercules, CA, USA) programmed with the following sequence of incubations: $10 \mathrm{~min}$ at $95^{\circ} \mathrm{C}, 40 \mathrm{cycles}$ of $15 \mathrm{~s}$ at $95^{\circ} \mathrm{C}, 30 \mathrm{~s}$ at $60^{\circ} \mathrm{C}$.

\subsubsection{Statistical Analysis}

Each experience was performed at least three times. Data are expressed as means \pm standard error (S.D.). The statistical analyses performed were one-way and two-way analyses of variance (ANOVA), followed by Tukey's test. Data analysis was performed in GraphPad Prisma 6 software. Here, $p$-values below 0.05 were considered statistically significant; ${ }^{*} p<0.05 ;{ }^{* *} p<0.01 ;{ }^{* * *} p<0.001 ;{ }^{* * *} p<0.0001$.

\section{Results and Discussion}

\subsection{Purification of mcDNA Vector}

Size exclusion chromatography was used to perform the purification of the mcDNA vector following the conditions previously described [28]. As expected in SEC, molecules such as genomic DNA and plasmid DNA elute quickly, whereas molecules such as RNA take a longer route through the pores of the matrix and are retarded in the chromatographic column. Fractions were selected, concentrated, and desalted with Vivaspin concentrators and analyzed using $0.8 \%$ agarose gel electrophoresis. The results showed that genomic DNA eluted mostly in the first peak, PP eluted mostly in the second peak, then mcDNA molecules eluted mostly in the third peak (see details in Supplementary Materials, Figure S3). The purified mcDNA vector (fractions from 10 to 15) was applied in in vitro transfection studies to verify its performance.

\subsection{Synthesis and Characterization of MPITC-R8 Conjugate}

After the procedure to synthesize the MPITC-R8 conjugate, the final product was analyzed by NMR (Figure 2). The chemical shifts at 7.3 and 1.5-2.0 in the 1NMR spectrum represented the aromatic protons present in MPITC and the methylene protons present in R8, respectively. The size exclusion chromatogram is shown in Figure S4 of the Supplementary Information. The relative molecular weight of MPITC-R8 is $1622 \mathrm{Da}$ (Table S1). The ratio of observed to theoretical molecular weights (0.987) indicated successful conjugation of MPITC and R8 at 1:1. 


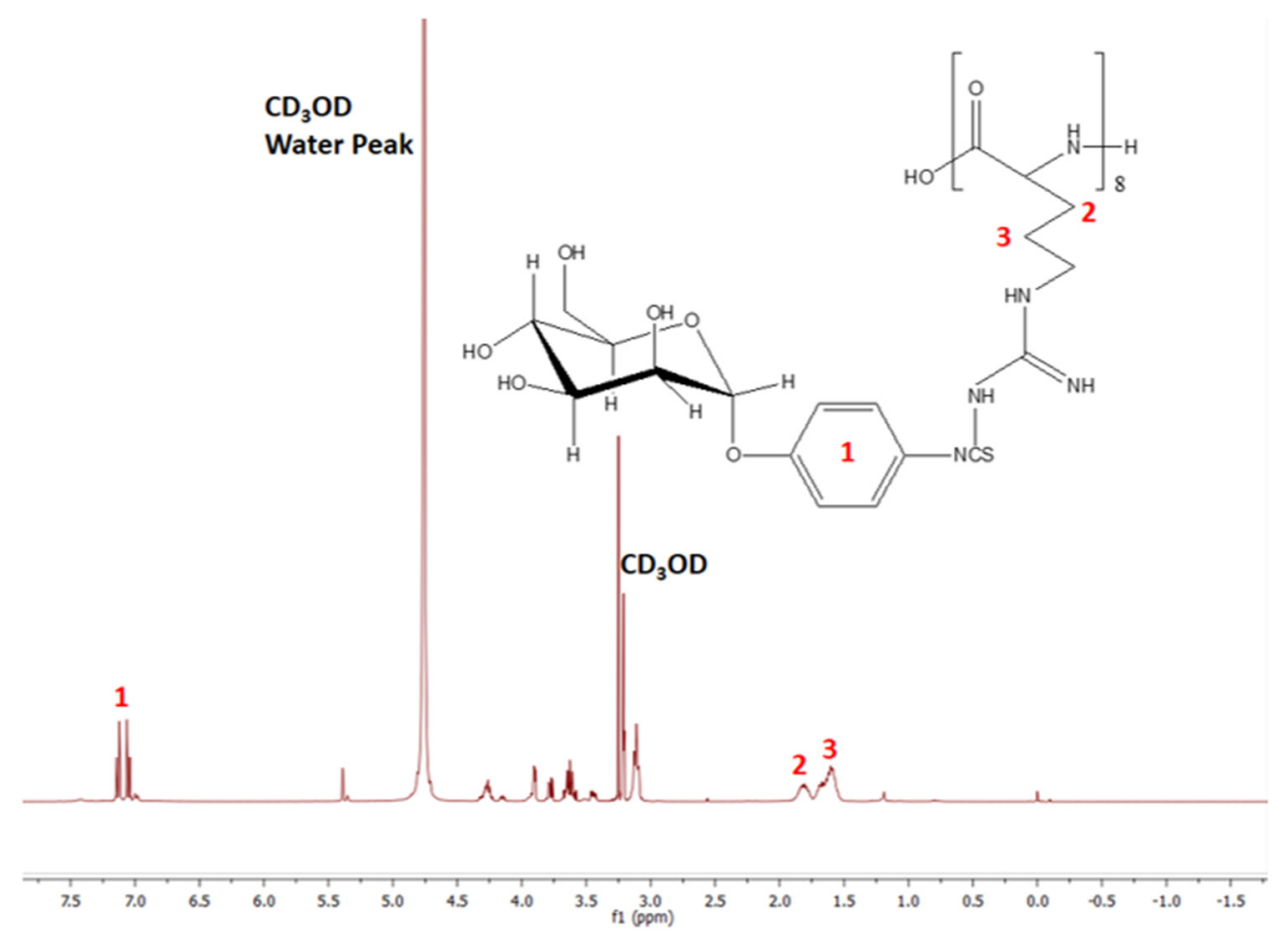

Figure 2. ${ }^{1} \mathrm{H}$ NMR spectrum of MPITC-R8 conjugate.

\subsection{The Properties of R8-Mannose/mcDNA and R8-Mannose/PEI/mcDNA Complexes}

The R8 peptide is a biocompatible and cationic CPP known to promote interaction and access to the inside of cells [29]. Its ability to bind, interact, and consequently condense DNA has been explored via the functionalization of systems for the delivery of genetic materials to eukaryotic cells [30,31]. Additionally, the PEI polymer has been widely applied in the formation of DNA-based systems, since it strongly interacts with DNA, condensing it and showing the capacity to efficiently deliver DNA both in vitro and in vivo [32]. PEI is a synthetic polymer that is highly soluble in water, positively charged, and whose cationic amines reduce the negative charge of DNA after complexation, causing its condensation [33]. A wide variety of ligands have also been explored to create functionalized and targeted delivery vehicles. The effectiveness of mannosylated devices is related to their ability to target mannose receptors, which are highly expressed on DCs and macrophages. Following this knowledge, the present study investigated the conception of mcDNA binary and ternary delivery systems, both of which were functionalized with mannose to enhance the interaction of formulations with macrophages.

Fourier transform infrared spectroscopy (FTIR) was used to evaluate interactions between components of each system, as well as for the presence of mannose. Figure 3 shows the FTIR spectra from different components and systems. 
A. $\mathrm{mcDNA}$

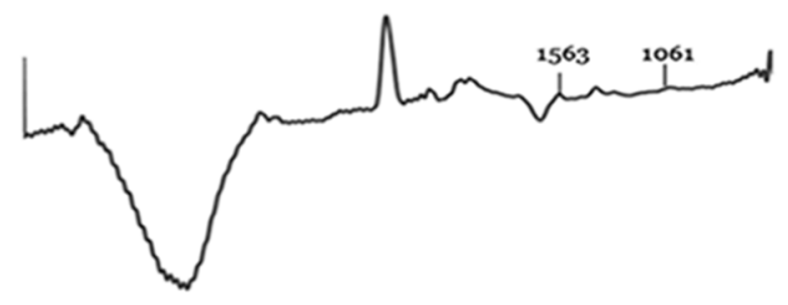

B. R8-mannose

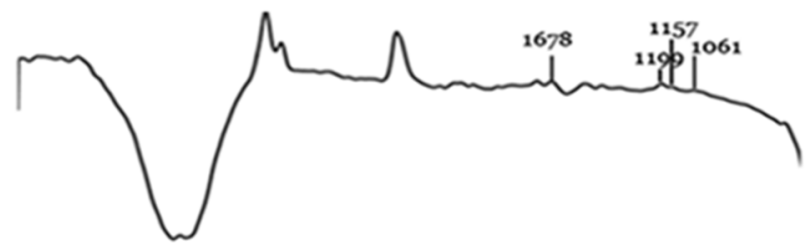

C. R8-mannose/mcDNA

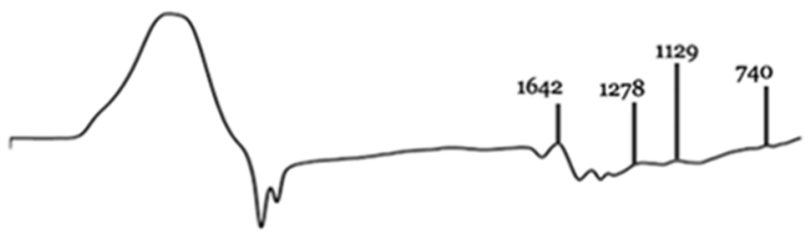

D. R8-mannose/PEI/mcDNA

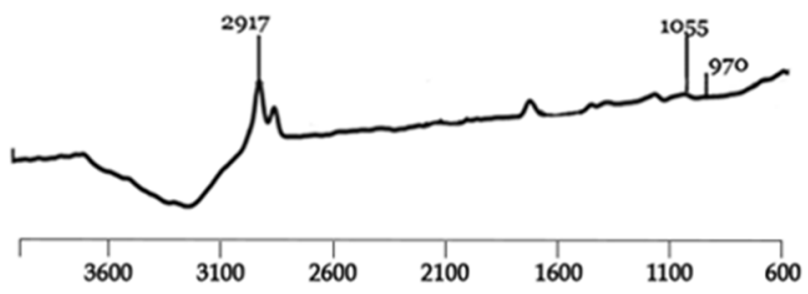

Figure 3. FTIR spectra (absorbance versus wavenumber) of mcDNA (A), R8-mannose (B), R8mannose/mcDNA (C), and R8-mannose/PEI/mcDNA (D) samples.

The spectrum of mcDNA (Figure 3A) presents peaks in the region of $1700-1500 \mathrm{~cm}^{-1}$ corresponding to the nitrogen bases, while the absorption peak seen at $1061 \mathrm{~cm}^{-1}$ is known to be related to ribose vibration (C-C sugar) [34]. The spectrum corresponding to the R8mannose conjugate (Figure 3B) shows absorption peaks characteristic of the octa-arginine peptide already identified in other studies. The prominent peak at $1678 \mathrm{~cm}^{-1}$ is attributed to the elongation of guanidine $\mathrm{N}=\mathrm{C}$ and carbonyl $\mathrm{C}=\mathrm{O}$ and the peaks at $1199 \mathrm{~cm}^{-1}$ and $1157 \mathrm{~cm}^{-1}$ are attributed to the elongation of $\mathrm{C}(\mathrm{O})-\mathrm{O}$ and $\mathrm{N}-\mathrm{C}$, respectively [35]. Peaks in the region of 1100 and $1000 \mathrm{~cm}^{-1}$ attributed to the $\mathrm{C}-\mathrm{O}$ vibration of the mannose suggest its presence on the system's surface [36,37]. The spectrum of the R8-mannose/mcDNA system (Figure 3C) suggests the existence of R8-mannose and mcDNA. The presence of R8 is evidenced by its characteristic absorption peaks, which suffered displacement due to the complexation process. It is possible to identify prominent peaks at $1642 \mathrm{~cm}^{-1}, 1278 \mathrm{~cm}^{-1}$, and $1129 \mathrm{~cm}^{-1}$. The spectrum of R8-mannose/PEI/mcDNA (Figure 3D) was analyzed in order to verify whether the addition of PEI would influence the surface compositions of the systems, confirming the presence of mannose. Thus, PEI polymer shows its most important peaks at approximately $1497 \mathrm{~cm}^{-1}$ and $1793 \mathrm{~cm}^{-1}$, representing the $\mathrm{N}-\mathrm{H}$ bonds that occur from encapsulation with the other components [38]. The absorption peak at $1055 \mathrm{~cm}^{-1}$ confirmed the presence of mannose. The absorbance peak at $970 \mathrm{~cm}^{-1}$ can be attributed to mcDNA. The comparison between the FTIR spectra before and after PEI conjugation 
confirmed its successful complexation to the R8-mannose/mcDNA system, as the amide group peaks of R8, mannose, and mcDNA were found.

Scanning electron microscopy was applied to identify the morphologies of the systems under study. Figure 4 shows images of these carriers prepared at several N/P ratios.
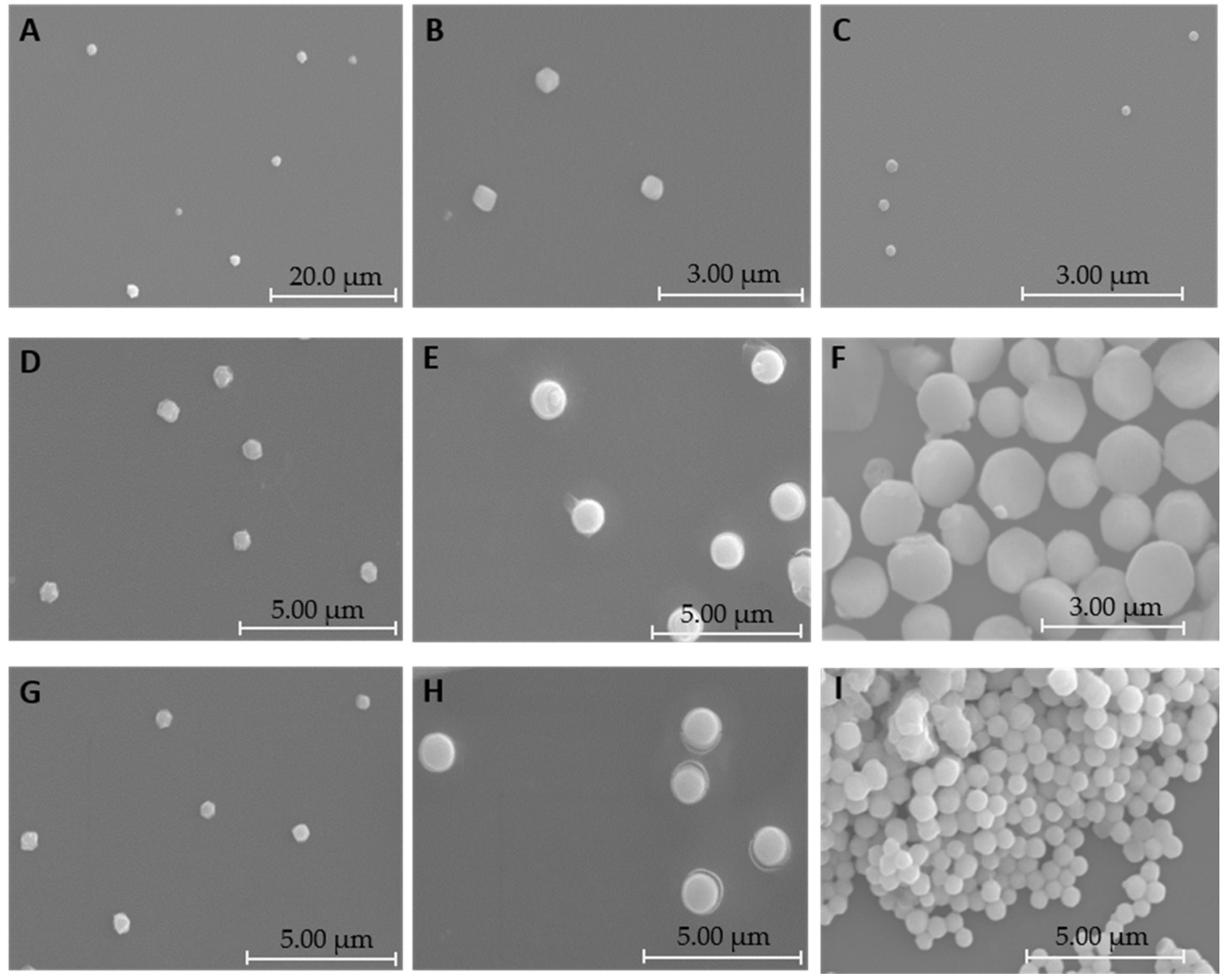

Figure 4. Scanning electron micrographs of particles formulated at the (A) R8-mannose/mcDNA N/P ratio of $1: 1$; (B) R8-mannose/mcDNA N/P ratio of 1.5:1; (C) R8-mannose/mcDNA N/P ratio of 2:1; (D) R8-mannose/PEI/mcDNA $\mathrm{N} / \mathrm{P}$ ratio of 1:5:1; (E) R8-mannose/PEI/mcDNA N/P ratio of 1.5:5:1; (F) R8-mannose/PEI/mcDNA N/P ratio of 2:5:1; (G) R8-mannose/PEI/mcDNA N/P ratio of 1:10:1; (H) R8-mannose/PEI/mcDNA N/P ratio of 1.5:10:1; and (I) R8mannose/PEI/mcDNA N/P ratio of 2:10:1.

Both systems exhibit an oval or spherical shape, which makes them suitable for a process of cellular internalization. Previous studies have shown that spherical shaped particles benefit cell uptake and transfection efficiency [39,40]. DLS experiments were performed to obtain information regarding the mean sizes and surface charges of binary and ternary systems formulated at different $\mathrm{N} / \mathrm{P}$ ratios. The respective results are presented in Figure 5. 


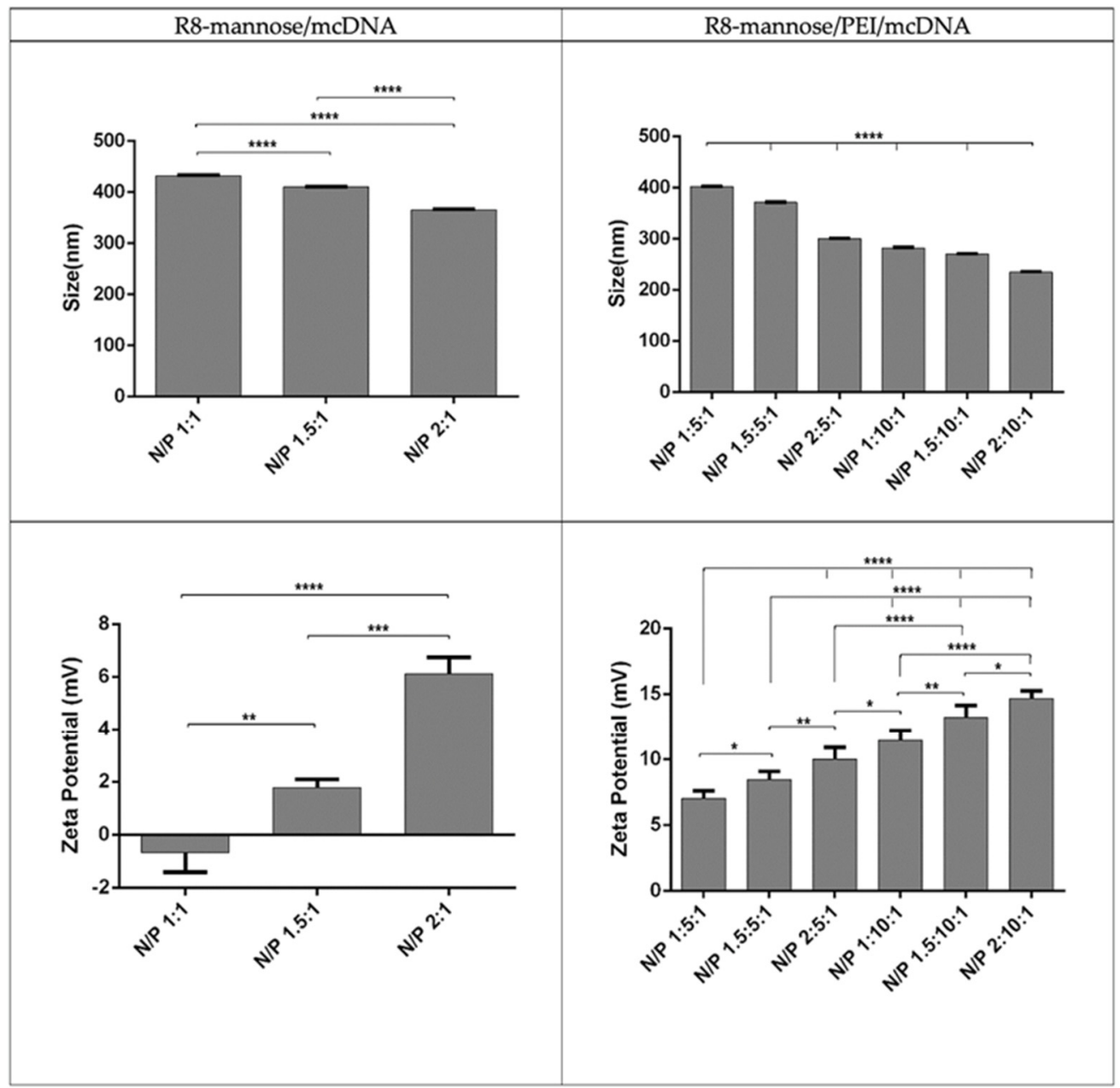

Figure 5. Mean sizes $(\mathrm{nm})$ of binary and ternary systems and average zeta potentials $(\mathrm{mV})$ of binary and ternary systems formulated at different $\mathrm{N} / \mathrm{P}$ ratios. The values were calculated with the data obtained from three independent measurements (mean \pm S.D., $n=3$ ); ${ }^{*} p<0.05 ;{ }^{* *} p<0.01 ;{ }^{* * *} p<0.001 ;{ }^{* * *} p<0.0001$.

Figure 5 shows that all particles are below $500 \mathrm{~nm}$. Additionally, and for all formulations, this parameter strongly varies with the $\mathrm{N} / \mathrm{P}$ ratio; it decreases with increments of the $\mathrm{N} / \mathrm{P}$ ratio. The size values obtained for particles of R8-mannose/PEI/mcDNA-E7 showed that by maintaining the N/P ratios for PEI (5 and 10) and changing only the N/P ratios for R8 (1,1.5, and 2), the particle size decreases, with the lowest value corresponding to the highest N/P ratio. The same kind of observation is valid for the situation where the R8 $\mathrm{N} / \mathrm{P}$ ratios were kept constant and the amine charges from PEI were varied, e.g., when PEI $\mathrm{N} / \mathrm{P}$ ratios of 5 and 10 were considered. Moreover, systems prepared at an R8 N/P ratio of 2 exhibit a significantly smaller size $(234.56 \mathrm{~nm})$ than for a PEI N/P ratio of 10 . Due to its primary, secondary, and tertiary amines, PEI shows higher positive charge at physiological $\mathrm{pH}$ compared to R8 peptide. PEI also exhibits impressive endosomolytic activity since it can change its ionization degree with its $\mathrm{pH}$. Additionally, the increasing molecular weight of PEI $(25 \mathrm{kDa})$ and the increase of its N/P ratio will resulted in the formation of more stable and smaller systems. This can, however, induce higher cytotoxicity [41]. Nevertheless, the results obtained confirm that the increase of the amine group content will result in a greater degree of mcDNA condensation, resulting in smaller complexes [32]. The high charge density and the great condensing capacity of both PEI and R8 enhance the strong interaction with the mcDNA, leading to the formation of smaller particles. 
In fact, an increase in the molecular weight of the PEI results in a decrease in the complex size and an increase in surface charge. However, for both linear and branched PEI structures, the N/P ratio is the determining parameter, since its variation can influence not only the size of the complexes but also the zeta potential they display. As the N/P ratio increases, the size of the complexes is reduced. Similarly, the effect of the N/P ratio on the surface charges is more pronounced as the N/P ratio increases [19].

Regarding the zeta potential values, it was found that R8-mannose/mcDNA-E7 system presents certain variations for the $\mathrm{N} / \mathrm{P}$ ratios tested. With the $\mathrm{N} / \mathrm{P}$ ratio increase, the zeta potential values become more positive. The $\mathrm{N} / \mathrm{P}$ ratio of $1: 1$ shows a negative value $(-0.67 \mathrm{mV})$, while systems with the highest tested ratio present positive surface charges (varying between +1.78 and $+6.11 \mathrm{mV}$ ). These results indicate that the negative mcDNA charges can be neutralized by increasing the N/P ratio. Regarding the zeta potential values achieved for the R8-mannose/PEI/mcDNA-E7 system, it is clear that maintaining the $\mathrm{N} / \mathrm{P}$ ratios of $\mathrm{PEI}$ and varying the $\mathrm{N} / \mathrm{P}$ ratios of $\mathrm{R} 8$-mannose or by maintaining only the $\mathrm{N} / \mathrm{P}$ ratios of $\mathrm{R} 8$-mannose and increasing the $\mathrm{N} / \mathrm{P}$ ratios of $\mathrm{PEI}$, there is an increment of the surface charge. The proportion of primary amines from the polymer in relation to phosphate groups from the plasmid results in an increase of the positive charge on the systems surface. The systems that proved to be the most suitable for delivery purposes based on size and surface charge were those prepared at an R8-mannose N/P ratio of 2 and PEI N/P ratio of 10, because they exhibit the smallest size $(234.56 \mathrm{~nm})$ and the highest zeta potential (+14.67). The formulation of mcDNA systems conjugated with PEI and R8-mannose results in the formation of ternary systems with higher positive zeta potential values when compared with R8-mannose binary systems. Some studies have reported the formation of complexes additionally packaged with PEI to construct ternary systems, which showed resistant properties against serum proteins and rapid cellular uptake, leading to improved gene transfer efficiency [41]. Song and collaborators prepared a novel polyethyleneimine-RRRRRRRR(R8)-heparin (HPR) nanogel as an efficient gene delivery system. The R8 peptide was grafted onto PEI (R8-PEI) to increase the charge density, reduce the toxicity of the gene delivery system, and thus enhance cellular uptake and gene transfection efficiency [42]. Our results from DLS measurements, showing that the addition of PEI to the R8-mannose/mcDNA-E7 system not only considerably reduces the size of particles but also increases the positive charge they carry, agree well with the results found in the literature.

\subsection{Stability Assay}

To evaluate the stability of both systems in the extracellular compartment and the protection that the systems confer to the DNA vector encoding HPV E7 gene, formulations at various $\mathrm{N} / \mathrm{P}$ ratios were incubated at 0,1 , and $4 \mathrm{~h}$ with DMEM medium supplemented with $10 \%$ FBS and with a trypsin solution at $37^{\circ} \mathrm{C}$. Figure 6 shows the obtained results. 
$\mathrm{DMEM}+10 \% \mathrm{FBS}$ incubation

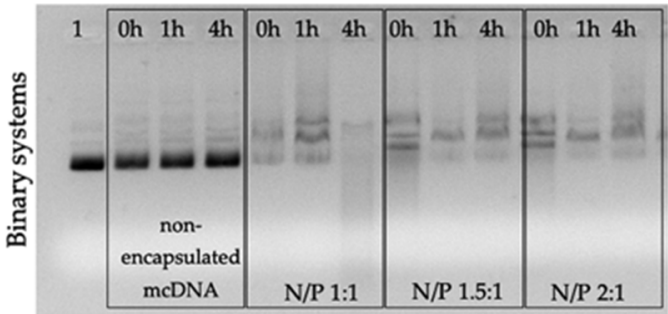

(A)

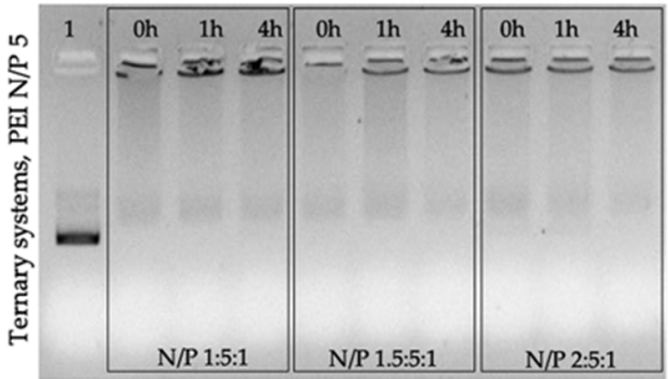

(C)

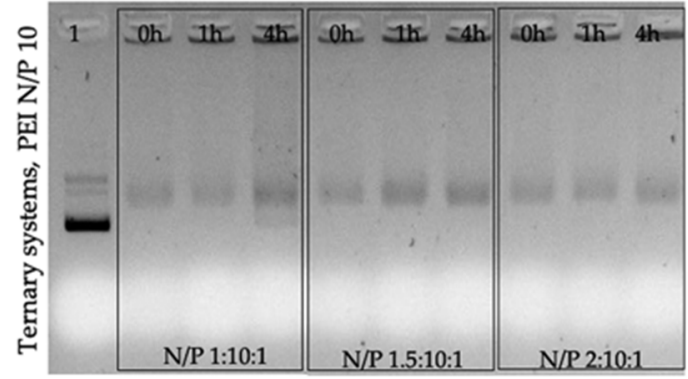

(E)
Trypsin incubation

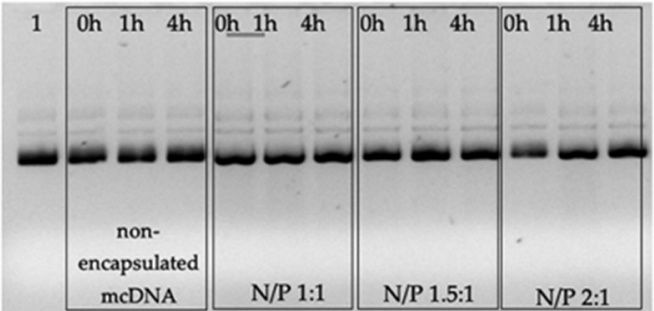

(B)

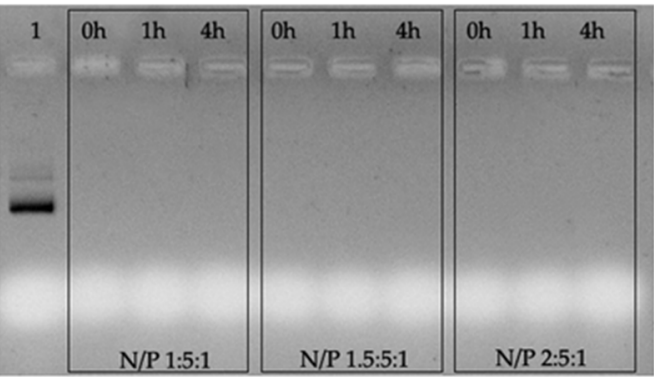

(D)

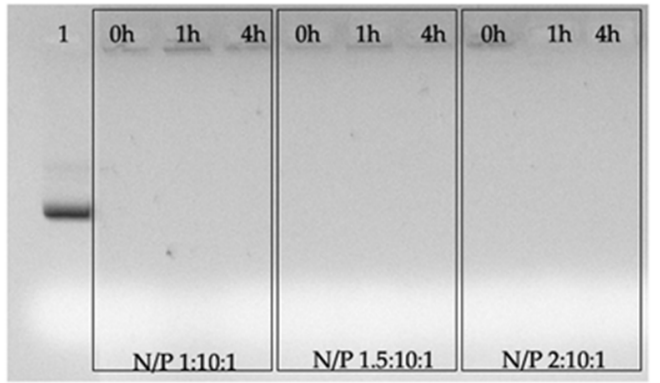

(F)

Figure 6. Electrophoretic analysis of mcDNA formulations after incubation with DMEM + 10\% FBS (A,C,E) and with trypsin (B,D,F): 1- mcDNA control; A and B: R8-mannose/mcDNA-E7; C and D: R8-mannose/PEI/mcDNA-E7 systems formulated by maintaining a PEI N/P ratio of 5 and changing R8 N/P ratios; E and F: R8-mannose /PEI/mcDNA-E7 systems formulated by maintaining PEI N/P ratio of 10 and changing R8 N/P ratios.

Data obtained for R8-mannose/mcDNA-E7 systems show the presence of mcDNA in the supernatants of all formulations conceived at different $\mathrm{N} / \mathrm{P}$ ratios at $0 \mathrm{~h}$ of incubation with the complete medium (Figure 6A). The electrophoretic profile also suggests a partial degradation of mcDNA in some cases. The same formulations were incubated with trypsin (Figure 6A) in another experiment to evaluate its action regarding the protection of the mcDNA-E7 vector. Once more, it was shown that the system is not able to maintain its integrity when incubated with trypsin. The decomplexation of mcDNA occurs at $0 \mathrm{~h}$ for the complete medium and trypsin incubations, suggesting the instability of these binary systems, which can compromise the protection, carriage, and in vitro and in vivo cell transfection efficiency [43]. On the other hand, the data obtained for R8mannose/PEI/mcDNA-E7 formulations at different R8-mannose N/P ratios and both PEI $\mathrm{N} / \mathrm{P}$ ratios (5 and 10) incubated with complete medium and trypsin at different times indicated the higher stability of ternary systems (Figure 6B,C). The electrophoretic migration of supernatants resulting from these experiments reveal absence of mcDNA in all incubations made with trypsin (Figure 6B,C) and a vestigial presence in incubation experiments with complete medium, mainly after $4 \mathrm{~h}$ period of incubation (Figure 6B,C). Curiously, this behavior is more evident in formulations with a PEI N/P ratio of 10 . Nevertheless, and as discussed before, PEI has a higher capacity to condense DNA as it interacts strongly with 
this molecule. Therefore, these data suggest that R8-mannose/PEI/mcDNA-E7 ternary systems are more suitable than R8-mannose/mcDNA-E7 binary systems for delivery of DNA vaccines, probably due to the presence of PEI [42].

\subsection{Biocompatibility Evaluation}

The biocompatibility of the developed systems was evaluated through resazurin assay on human fibroblast and Raw 264.7 cells to determine if the studied systems had any toxic effect towards the cells once transfected. The results on human fibroblast and Raw 264.7 cells at 24 and $48 \mathrm{~h}$ for the various carriers at different $\mathrm{N} / \mathrm{P}$ ratios are summarized in Figure 7.

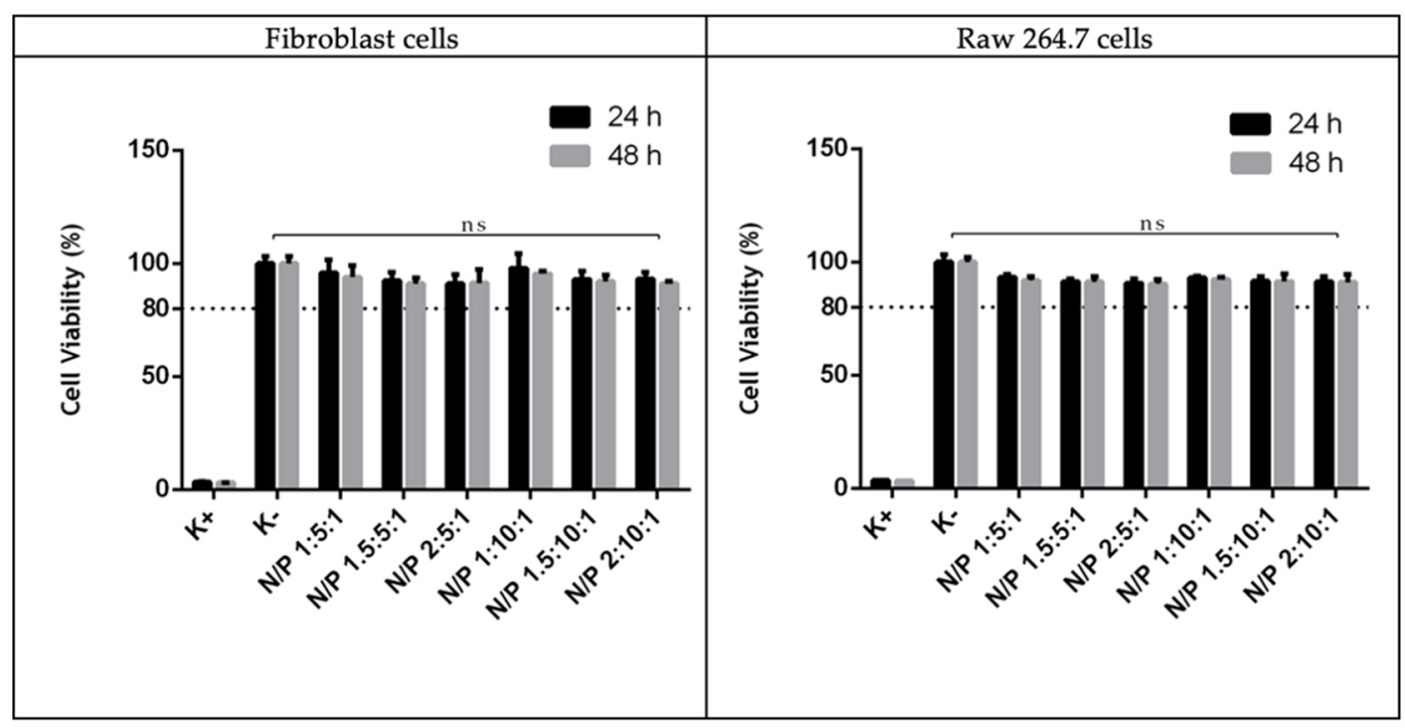

Figure 7. Cellular viability of human fibroblast and Raw 264.7 cells after 24 and $48 \mathrm{~h}$ incubation with R8-mannose/PEI/mcDNA particles at various N/P ratios. Percent viability is expressed relative to negative control cells. Non-transfected cells were used as negative control. Data obtained from three independent measurements (mean \pm S.D., $n=3$ ).

It was observed that none of particles are toxic to the Human fibroblast cells since cellular viability shows values superior to $80 \%$ regardless the transfection period. The results on Raw 264.7 cells are identical once all systems have a viability greater than $80 \%$ even $48 \mathrm{~h}$ after transfection. Branched PEI polymers are known to compact DNA more efficiently due to the higher density of its primary amine groups. However, the cytotoxic effect associated with branched polymer structures must be taken into consideration, especially with branched PEI $25 \mathrm{kDa}$ since it can induce cell membrane damage and initiate apoptosis. As found before, the molecular weight, the architecture of the polymer and the $\mathrm{N} / \mathrm{P}$ ratio are all relevant parameters that can influence cellular viability. The $\mathrm{N} / \mathrm{P}$ ratio appears to be the main factor determining cellular viability as branched PEI polymers are only biocompatible for the lower $\mathrm{N} / \mathrm{P}$ ratios. The higher the $\mathrm{N} / \mathrm{P}$ ratio used at vector preparation step, the higher the cytotoxicity of PEI $25 \mathrm{kDa}$. Nevertheless, it does not compromise its use, at least, until $\mathrm{N} / \mathrm{P}$ ratio 15 . To reduce the cellular toxic effects of branched PEI $25 \mathrm{kDa}$, lower $\mathrm{N} / \mathrm{P}$ ratios should be considered so as not to increase the content of free amines that are responsible for cytotoxicity [19]. Considering that some studies report percentages of cell viability above $80 \%$ are considered non-cytotoxic [44], these results confirm an improvement in biocompatibility of PEI-based vectors, probably due to the presence of $\mathrm{R} 8$ peptide on the formulations.

\subsection{Cellular Uptake and Intracellular Location of Complexes}

The capacity for cellular uptake and internalization of the developed systems was evaluated. The uptake of PEI/mcDNA and R8-mannose/PEI/mcDNA systems into Raw 
264.7 cells and their intracellular co-localization after $3 \mathrm{~h}$ of transfection was visualized by fluorescence confocal microscopy. The images are presented in Figure 8.

$\begin{array}{lll}\text { mCDNA-FITC } & \text { DAPI } & \text { Merged }\end{array}$

A

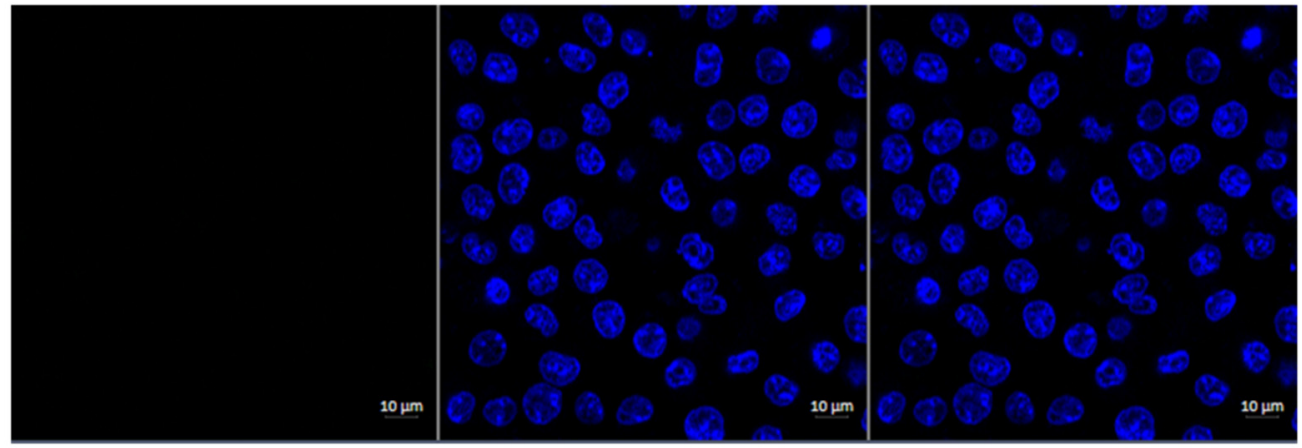

B

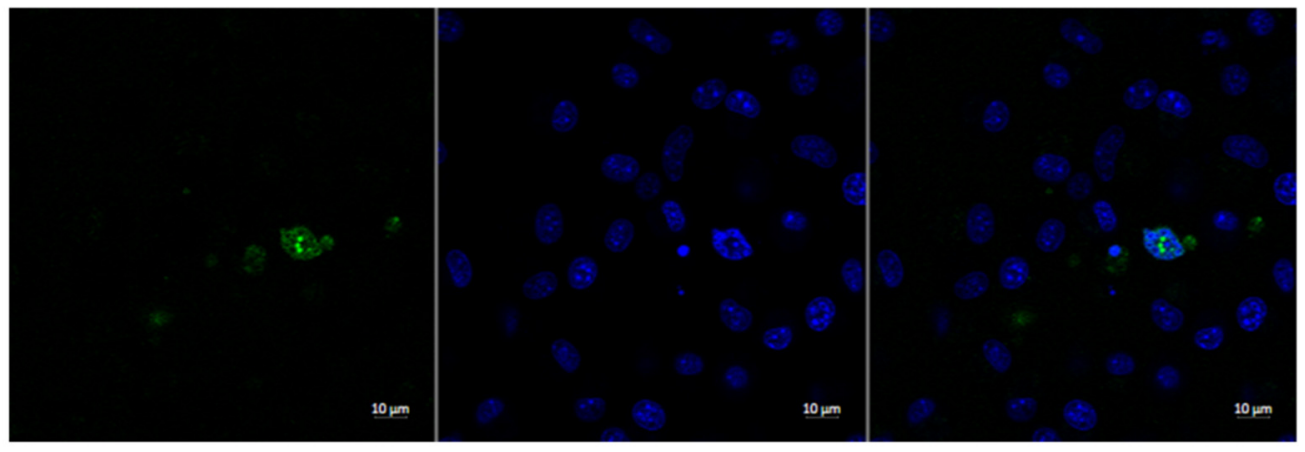

C

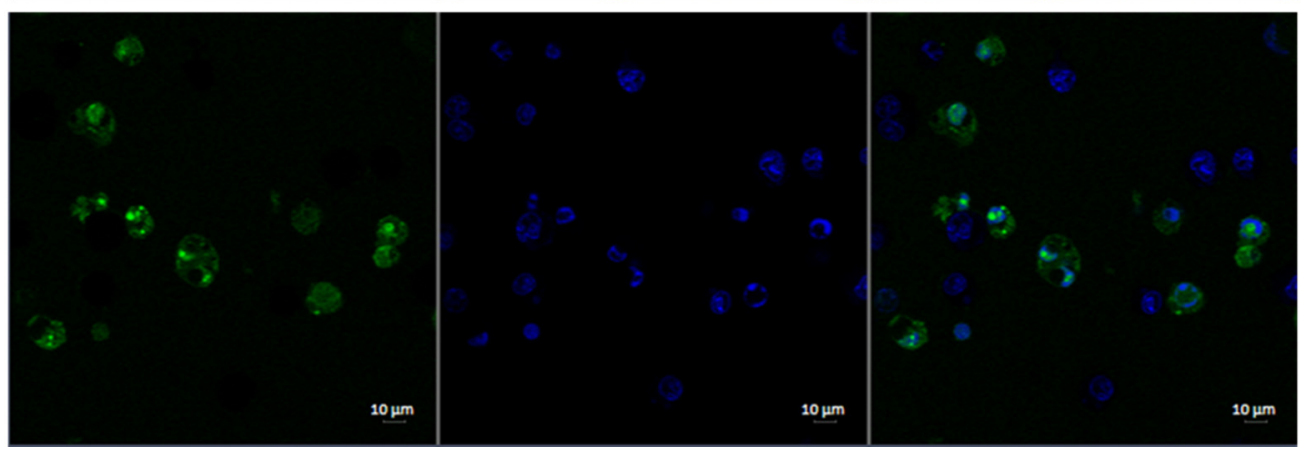

Figure 8. The transfection ability and intracellular co-localization of PEI/mcDNA (N/P ratio of 5:1) and R8-mannose/PEI/ mcDNA (N/P ratio of 2:5:1) systems was investigated by fluorescence confocal microscopy. Nuclei were stained blue by DAPI, while green represents the mcDNA stained with FITC. Live cell images: Raw 264.7 non-transfected cells (A); Raw 264.7 cells after $3 \mathrm{~h}$ of transfection with PEI/mcDNA (N/P ratio of 5:1) system (B) and Raw 264.7 cells after $3 \mathrm{~h}$ of transfection with R8-mannose/PEI/mcDNA (N/P ratio of 2:5:1) system $(\mathrm{C})$.

Nuclei were stained blue by DAPI, while green represented the mcDNA stained with FITC. The cell live imaging presented in Figure 8A corresponding to non-transfected cells (control) shows that cells do not exhibit green fluorescence signals. According to Figure 8B, corresponding to PEI/mcDNA formulations in the absence of R8-mannose, it is clear that mcDNA systems have less ability to reach the nuclei of target cells. Figure $8 \mathrm{C}$, corresponding to the transfection mediated by R8-mannose/PEI/mcDNA systems, shows the presence of stained mcDNA into the cells, revealing higher ability from these systems to reach the nuclei of target cells. Therefore, the results suggest that these systems are able to overcome both extracellular and intracellular barriers and the presence of R8-mannose seems to efficiently improve the cell entry, internalization, and mcDNA accumulation into the nucleus $[15,45]$. Once inside the nucleus, it is expected that transcription and expression of the target gene will occur. 


\subsection{Expression of E7 Gene}

The cellular transfection mediated by PEI/mcDNA systems was monitored in the absence and presence of R8-mannose to evaluate the influence on the systems this process, namely on E7 gene expression. The characteristics exhibited by the PEI/mcDNA complexes are strongly dependent on the $\mathrm{N} / \mathrm{P}$ ratio used. A higher $\mathrm{N} / \mathrm{P}$ ratio leads to a strong polymer amine density that can efficiently condense the mcDNA molecule and form delivery systems with a higher positive charge, favoring the interaction with negatively charged proteoglycans present in the cell membrane and facilitating their entry into the cell [46].

RT-PCR was used to evaluate the transcription efficiency of the E7 gene into the cells transfected by PEI/mcDNA and R8-mannose/PEI/mcDNA systems. Non-transfected cells were used as control and amplification of E7 transcripts was performed using specific primers. Samples were then analyzed using $1 \%$ agarose gel electrophoresis, the results of which are presented in Figure S5. However, as the assessment of the band intensities was in some cases unclear, the RT-qPCR technique was employed to quantify E7 expression levels, as this is a more precise method allowing for an accurate evaluation. The obtained results for gene expression after transfection with the developed systems are presented in Figure 9 .
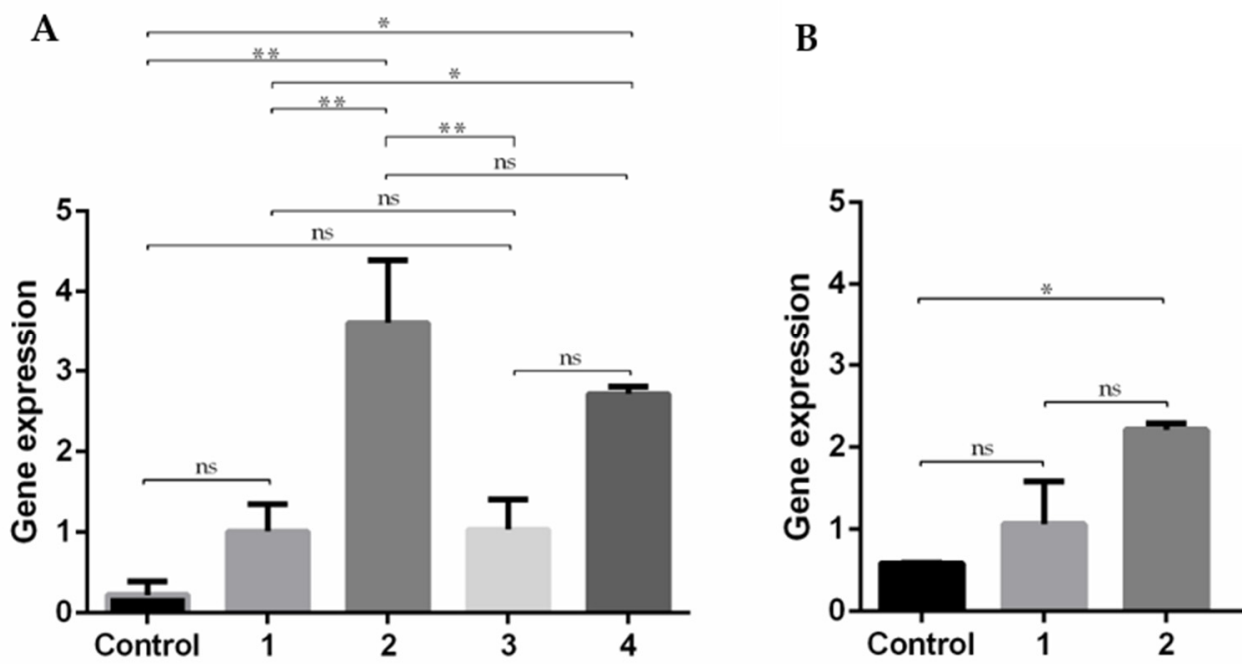

Figure 9. RT-qPCR of E7 expression levels in RAW 264.7 cells (A) and human fibroblast cells (B): Control-non-transfected cells; 1 - PEI/mcDNA N/P ratio 5:1; 2- R8-mannose/PEI/mcDNA N/P ratio 2:5:1; 3- PEI/mcDNA N/P ratio 10:1; 4R8-mannose/PEI/mcDNA N/P ratio 2:10:1. Data obtained from three independent measurements (mean \pm S.D., $n=3$ ); ${ }^{*} p<0.05$; ${ }^{* *} p<0.01$ : ns-no significance.

As shown in Figure 9, there is a general increase in the expression of E7 transcripts in relation to non-transfected cells (control). In the RAW 264.7 cell line, R8-mannose/PEI/mcDNA ternary systems show higher levels of E7 transcripts when compared to PEI/mcDNA binary systems. These results are in agreement with the previous tendency observed in confocal experiments (Figure 8), suggesting that the presence of R8-mannose influences the systems' internalization, therefore favoring the subsequent processes of nucleus targeting and gene expression. In fact, this behavior could be related to the presence of the R8 peptide, which has shown quite satisfactory results in terms of cell membrane uptake and nuclear localization $[14,16]$. R8-mannose/PEI/mcDNA ternary systems at a PEI N/P ratio of 5 have higher levels of gene transcription than ternary systems at a PEI N/P ratio of 10 . These results indicate that the PEI N/P ratio of 10 can reduce the proportion of R8-mannose included in the ternary system (probably due to the charge repulsion), decreasing the positive effects of this mannose-R8 conjugate in terms of cell recognition and internalization, consequently affecting the transcription of the E7 gene. 
As the PEI/mcDNA N/P ratio of 5:1 and R8-mannose/PEI/mcDNA N/P ratio of 2:5:1 showed successful results in Raw 264.7 cells, they were chosen in an attempt to understand and clarify the influence of R8-mannose in human fibroblast cells (Figure 9B). The obtained results followed the same tendency as for RAW 264.7 cells, since ternary systems showed higher levels of E7 transcripts than binary systems, suggesting a positive influence of R8 in cell uptake and nucleus accumulation [15,31]. However, comparing the E7 gene transcription obtained by the R8-mannose/PEI/mcDNA ternary system in both cell lines, higher levels were attained in Raw 264.7 cells than in human fibroblast cells. These results could be related to the cumulative effects of mannose ligands, which can improve the system internalization through the recognition of mannose receptors of RAW cells. It is well known that Raw 264.7 cells expressing moderate mannose receptors might constitute a suitable and valuable opportunity to investigate the transfection efficiency of mannosylated systems [24,45]. Some studies have reported applications of mannosylated systems with improved transfection efficiency, whose results confirm that mannosylated systems are more effective for gene transcription and expression in Raw 264.7 cells [24]. Once again, the results suggest that the presence of both mannose and R8 may influence the extent of cellular internalization of the systems, preferentially by APCs such as macrophages. This fact in turn may dictate the success of gene transcription and consequently protein expression, and therefore the therapeutic effect.

A successful anti-cancer vaccine depends on its ability to induce humoral and cellular immunity against a specific antigen. Antigens are known to be delivered by various dendritic cell receptors, including C-type lectin receptors (CLRs), which are important pattern recognition receptors involved in the induction of adaptive immunity against pathogens $[47,48]$. Numerous receptors expressed on DCs have been identified, and each of them have shown potential as targets for cancer vaccine design. Most studies to date have used mannose to target the mannose receptors, as it is highly expressed on DCs and macrophages and plays a key role in antigen recognition $[45,48]$. However, some studies have shown good results with other CLRs, such as langerin, DC-SIGN, and others. A comparative study between DC-SIGN and langerin showed functional differences, despite similarities in carbohydrate recognition domains. As with mannose receptors, DC -SIGN also recognizes carbohydrates on pathogens mediating endocytosis, thereby activating the adaptive immune response against pathogens [47-49]. Although our data show evidence of efficient E7 gene transfection via the developed R8 mannose/PEI/mcDNA-E7 systems, further studies are needed to evaluate the immune response. It would also be relevant to verify whether these nanoparticles, when recognized by pathogen recognition receptors such as C-type lectin, could stimulate the immune response, and thus serve as vaccine adjuvants.

\section{Conclusions}

The main challenge associated with DNA vaccines and its main limitation for clinical application is the delivery barriers to targeted immune cells, which obstruct the stimulation of effective antigen-specific immune responses in humans, which ultimately, leads to low therapeutic efficacy. In this report, novel delivery systems have been developed, aiming to add a significant contribution to DNA vaccines by exploring the assets of non-viral systems. Pursuing this goal, R8-mannose/mcDNA-E7 binary and R8-mannose/PEI/mcDNA-E7 ternary systems have been conceived at several $\mathrm{N} / \mathrm{P}$ ratios and their physicochemical properties have been assessed. The carriers have shown a set of properties related to their morphology, size, surface charge, and cytotoxic profile, which opens the possibility to use them as suitable delivery vehicles. In vitro studies and a comparison between the formulated carriers revealed that R8-mannose/PEI/mcDNA-E7 systems are more functional DNA vaccine delivery carriers. These ternary systems, either incubated with trypsin or DMEM medium, were able to efficiently condense mcDNA, since there was no evidence of decomplexation or degradation of particles. The addition of the PEI to the R8-mannose/mcDNA-E7 system not only considerably reduces the size of the particles but also increases the zeta potential; the vectors were also revealed to be biocompatible. 
Finally, expression of the E7 gene was more intense with ternary systems, which suggests the influence of mannose and R8 for receptor recognition and cellular internalization. To guarantee a better effect of R8-mannose/PEI in the recognition of mannose receptors and internalization by R8, control of the proportion of PEI is needed.

This work constitutes a significant advance in the conception of non-viral delivery systems to carry DNA vaccines, offering to this field a suitable tool to be further evaluated.

Supplementary Materials: The following are available online at https: / www.mdpi.com/article / 10.3390/pharmaceutics13050673/s1: Figure S1: Schematic representation of three mutations in the HPV E7 gene and cloning of mutated genes in the parental plasmid vector. (A) E7 gene sequence from HPV wildtype. (B) Identification of three mutations in the HPV E7 wildtype gene. (C) Sequencing of E7 mutant gene. (D) cloning of E7 mutant gene in the parental plasmid vector. Figure S2: Chromatographic profile of mcDNA isolated by size exclusion chromatography in the Sephacryl SF-1000 column (A), using the following conditions: flow-rate of $0.3 \mathrm{~mL} / \mathrm{min}$, sample loading of $2 \mathrm{~mL}$ and fractionation of $3 \mathrm{~mL}$; and agarose gel electrophoresis of fractions from peak III (B). Figure S3: SEC chromatogram of MPITC-R8. Figure S4. Electrophoretic mobility of supernatants from several formulations studied at various N/P ratios. (A) R8-mannose/mcDNA. (B) R8-mannose/PEI/mcDNA maintaining PEI N/P ratio at 5 and changing $\mathrm{R} 8 \mathrm{~N} / \mathrm{P}$ ratios. (C) R8-mannose/PEI/mcDNA maintaining PEI N/P ratio at 10 and changing $\mathrm{R} 8 \mathrm{~N} / \mathrm{P}$ ratios. Image A: lane 1-R8-mannose/mcDNA N/P ratio of 1:1; lane 2-R8-mannose/mcDNA N/P ratio of 1.5:1; lane 3-R8-mannose/mcDNA N/P ratio of 2:1. Image $\mathrm{B}$ : lane 1-R8-mannose/PEI/mcDNA N/P ratio of 1:5:1; lane 2-R8-mannose/PEI/mcDNA N/P ratio of 1.5:5:1; lane 3-R8-mannose/PEI/mcDNA $\mathrm{N} / \mathrm{P}$ ratio of 2:5:1. Image $\mathrm{C}$ : lane $1-\mathrm{R} 8$-mannose/PEI/mcDNA $\mathrm{N} / \mathrm{P}$ ratio of 1:10:1: lane 2-R8mannose/PEI/mcDNA N/P ratio of 1.5:10:1; lane 3-R8-mannose/PEI/mcDNA N/P ratio of 2:10:1. Figure S5. Analysis of RT-PCR products by agarose gel electrophoresis. Evaluation of E7 transcripts in Raw cells (A) and fibro cells (B). Lane 1-DNA molecular weight marker; lane 2-control without cDNA sample; lane 3-non-transfected cells; lane 4-cells transfected by PEI/mcDNA N/P ratio 5:1; lane 5-cells transfected by R8-mannose/PEI/mcDNA N/P ratio 2:5:1; lane 6-cells transfected by $\mathrm{PEI} / \mathrm{mcDNA} \mathrm{N} / \mathrm{P}$ ratio 10:1; lane 7-cells transfected by R8-mannose/PEI/mcDNA N/P ratio 2:10:1. Table S1: The molecular weight of each MPITC-R8 conjugate by SEC analysis.

Author Contributions: A.S.S., conceptualization, methodology, software, formal analysis, investigation, data curation, writing-original draft preparation. D.E., A.R.N. and T.A. methodology, software, formal analysis, investigation, data curation. H.B. conceptualization, methodology, software, formal analysis. S.B. methodology, validation, formal analysis, investigation, writing-review and editing. D.C. validation, formal analysis, investigation, resources, writing-review and editing, supervision, funding acquisition; Â.S. methodology, software, validation, formal analysis, investigation, resources, data curation, writing - review and editing, visualization, supervision, project administration. All authors have read and agreed to the published version of the manuscript.

Funding: This work was financed by the Foundation for Science and Technology (FCT), through funds from the State Budget, and by the European Regional Development Fund (ERDF), under the Portugal 2020 Program, through the Regional Operational Program of the Center (Centro2020), through the Project with the reference UIDB/00709/2020. D.E., A.R.N. and T.A. acknowledge the doctoral fellowships (references 2020.10201.BD, 2020.08310.BD and SFRH/BD/148406/2019 respectively) from FCT. D.C. acknowledges the FCT program contract IF/01459/2015 supported by Fundo Social Europeu e Programa Operacional Potencial Humano.

Conflicts of Interest: The authors declare no conflict of interest.

\section{References}

1. Almeida, A.M.; Queiroz, J.A.; Sousa, F.; Sousa, Â. Cervical cancer and HPV infection: Ongoing therapeutic research to counteract the action of E6 and E7 oncoproteins. Drug Discov. Today 2019, 24, 2044-2057. [CrossRef]

2. Chan, C.K.; Aimagambetova, G.; Ukybassova, T.; Kongrtay, K.; Azizan, A. Human Papillomavirus Infection and Cervical Cancer: Epidemiology, Screening, and Vaccination-Review of Current Perspectives. J. Oncol. 2019, 2019, 3257939. [CrossRef] [PubMed]

3. Harden, M.E.; Munger, K. Human papillomavirus molecular biology. Mutat. Res. Rev. Mutat. Res. 2017, 772, 3-12. [CrossRef] [PubMed]

4. Peralta-Zaragoza, O.; Bermúdez-Morales, V.H.; Pérez-Plasencia, C.; Salazar-León, J.; Gómez-Cerón, C.; Madrid-Marina, V. Targeted treatments for cervical cancer: A review. OncoTargets Ther. 2012, 5, 315-328. [CrossRef] [PubMed] 
5. Almeida, A.M.; Queiroz, J.A.; Sousa, F.; Sousa, Â. Minicircle DNA: The Future for DNA-Based Vectors? Trends Biotechnol. 2020, 38, 1047-1051. [CrossRef] [PubMed]

6. Petkar, K.C.; Patil, S.M.; Chavhan, S.S.; Kaneko, K.; Sawant, K.K.; Kunda, N.K.; Saleem, I.Y. An Overview of Nanocarrier-Based Adjuvants for Vaccine Delivery. Pharmaceutics 2021, 13, 455. [CrossRef]

7. Shi, B.; Zheng, M.; Tao, W.; Chung, R.; Jin, D.; Ghaffari, D.; Farokhzad, O.C. Challenges in DNA Delivery and Recent Advances in Multifunctional Polymeric DNA Delivery Systems. Biomacromolecules 2017, 18, 2231-2246. [CrossRef]

8. Thomas, T.J.; Tajmir-Riahi, H.-A.; Pillai, C.K.S. Biodegradable Polymers for Gene Delivery. Molecules 2019, 24, 3744. [CrossRef]

9. Ruseska, I.; Zimmer, A. Internalization mechanisms of cell-penetrating peptides. Beilstein J. Nanotechnol. 2020, 11, 101-123. [CrossRef] [PubMed]

10. Lehto, T.; Kurrikoff, K.; Langel, Ü. Cell-penetrating peptides for the delivery of nucleic acids. Expert Opin. Drug Deliv. 2012, 9, 823-836. [CrossRef]

11. Böhmová, E.; Machová, D.; Pechar, M.; Pola, R.; Venclíková, K.; Janoušková, O.; Etrych, T. Cell-penetrating peptides: A useful tool for the delivery of various cargoes into cells. Physiol. Res. 2018, 67, S267-S279. [CrossRef]

12. Takeuchi, T.; Futaki, S. Current Understanding of Direct Translocation of Arginine-Rich Cell-Penetrating Peptides and Its Internalization Mechanisms. Chem. Pharm. Bull. 2016, 64, 1431-1437. [CrossRef]

13. Rompicharla, S.V.K.; Kumari, P.; Ghosh, B.; Biswas, S. Octa-arginine modified poly(amidoamine) dendrimers for improved delivery and cytotoxic effect of paclitaxel in cancer. Artif. Cells Nanomed. Biotechnol. 2018, 46, 847-859. [CrossRef]

14. Zhang, X.; Wang, H.; Coulter, J.A.; Yang, R. Octaarginine-modified gold nanoparticles enhance the radiosensitivity of human colorectal cancer cell line LS180 to megavoltage radiation. Int. J. Nanomed. 2018, 13, 3541-3552. [CrossRef] [PubMed]

15. Biswas, S.; Dodwadkar, N.S.; Deshpande, P.P.; Parab, S.; Torchilin, V.P. Surface functionalization of doxorubicin-loaded liposomes with octa-arginine for enhanced anticancer activity. Eur. J. Pharm. Biopharm. 2013, 84, 517-525. [CrossRef]

16. Bhatt, H.; Ghosh, B.; Biswas, S. Cell-Penetrating Peptide and $\alpha$-Tocopherol-Conjugated Poly(amidoamine) Dendrimers for Improved Delivery and Anticancer Activity of Loaded Paclitaxel. ACS Appl. Bio Mater. 2020, 3, 3157-3169. [CrossRef]

17. Xun, M.M.; Huang, Z.; Xiao, Y.P.; Liu, Y.H.; Zhang, J.; Zhang, J.H.; Yu, X.Q. Synthesis and Properties of Low-Molecular-Weight PEI-Based Lipopolymers for Delivery of DNA. Polymers 2018, 10, 1060. [CrossRef] [PubMed]

18. Hamada, E.; Kurosaki, T.; Hashizume, J.; Harasawa, H.; Nakagawa, H.; Nakamura, T.; Kodama, Y.; Sasaki, H. Anionic Complex with Efficient Expression and Good Safety Profile for mRNA Delivery. Pharmaceutics 2021, 13, 126. [CrossRef] [PubMed]

19. Costa, D.; Valente, A.J.M.; Queiroz, J.A.; Sousa, Â. Finding the ideal polyethylenimine-plasmid DNA system for co-delivery of payloads in cancer therapy. Colloids Surf. B Biointerfaces 2018, 170, 627-636. [CrossRef]

20. Lim, M.; Badruddoza, A.Z.M.; Firdous, J.; Azad, M.; Mannan, A.; Al-Hilal, T.A.; Cho, C.S.; Islam, M.A. Engineered Nanodelivery Systems to Improve DNA Vaccine Technologies. Pharmaceutics 2020, 12, 30. [CrossRef] [PubMed]

21. Hobernik, D.; Bros, M. DNA Vaccines-How Far From Clinical Use? Int. J. Mol. Sci. 2018, 19, 3605. [CrossRef]

22. Jariwala, S.P. The role of dendritic cells in the immunopathogenesis of psoriasis. Arch. Pharmacal Res. 2007, 299, 359-366. [CrossRef] [PubMed]

23. Hu, Y.; Xu, B.-H.; Xu, J.-J.; Shou, D.; Gao, J.-Q. Synthesis of Mannosylated Polyethylenimine and Its Potential Application as Cell-Targeting Non-Viral Vector for Gene Therapy. Polymers 2014, 6, 2573-2587. [CrossRef]

24. Shilakari Asthana, G.; Asthana, A.; Kohli, D.V.; Vyas, S.P. Mannosylated Chitosan Nanoparticles for Delivery of Antisense Oligonucleotides for Macrophage Targeting. BioMed Res. Int. 2014, 2014, 526391. [CrossRef]

25. Hu, Z.; Shi, X.; Yu, B.; Li, N.; Huang, Y.; He, Y. Structural Insights into the pH-Dependent Conformational Change and Collagen Recognition of the Human Mannose Receptor. Structure 2018, 26, 60-71.e63. [CrossRef] [PubMed]

26. Eusébio, D.; Almeida, A.M.; Alves, J.M.; Maia, C.J.; Queiroz, J.A.; Sousa, F.; Sousa, Â. The Performance of Minicircle DNA Versus Parental Plasmid in p53 Gene Delivery Into HPV-18-Infected Cervical Cancer Cells. Nucleic Acid Ther. 2021, 31, 82-91. [CrossRef]

27. Diogo, M.; Queiroz, J.; Monteiro, G.; Martins, S.; Ferreira, G.; Prazeres, D. Purification of a cystic fibrosis plasmid vector for gene therapy using hydrophobic interaction chromatography. Biotechnol. Bioeng. 2000, 68, 576-583. [CrossRef]

28. Almeida, A.M.; Eusébio, D.; Queiroz, J.A.; Sousa, F.; Sousa, A. The use of size-exclusion chromatography in the isolation of supercoiled minicircle DNA from Escherichia coli lysate. J. Chromatogr. A 2019, 1609, 460444. [CrossRef]

29. Koshkaryev, A.; Piroyan, A.; Torchilin, V.P. Bleomycin in octaarginine-modified fusogenic liposomes results in improved tumor growth inhibition. Cancer Lett. 2013, 334, 293-301. [CrossRef]

30. Futaki, S. Arginine-rich peptides: Potential for intracellular delivery of macromolecules and the mystery of the translocation mechanisms. Int. J. Pharm. 2002, 245, 1-7. [CrossRef]

31. Futaki, S. Membrane-permeable arginine-rich peptides and the translocation mechanisms. Adv. Drug Deliv. Rev. 2005, 57, 547-558. [CrossRef] [PubMed]

32. Sousa, Â.; Almeida, A.M.; Faria, R.; Konate, K.; Boisguerin, P.; Queiroz, J.A.; Costa, D. Optimization of peptide-plasmid DNA vectors formulation for gene delivery in cancer therapy exploring design of experiments. Colloids Surf. B Biointerfaces 2019, 183, 110417. [CrossRef] [PubMed]

33. Choosakoonkriang, S.; Lobo, B.A.; Koe, G.S.; Koe, J.G.; Middaugh, C.R. Biophysical characterization of PEI/DNA complexes. J. Pharm. Sci. 2003, 92, 1710-1722. [CrossRef] [PubMed]

34. Mady, M.; Awad, W.; El-Guendy, N.; Elsayed, A. Interaction of DNA and Polyethylenimine: FTIR and DSC Studies. Phys. Sci. Int. J. 2011, 6, 7328-7334. 
35. Imani, R.; Hojjati Emami, S.; Faghihi, S. Synthesis and Characterization of Octaarginine Functionalized Graphene Oxide Nano-carrier for Gene Delivery Applications. Phys. Chem. Chem. Phys. 2015, 17, 6328-6339. [CrossRef]

36. Costa, A.; Sarmento, B.; Seabra, V. Mannose-functionalized solid lipid nanoparticles are effective in targeting alveolar macrophages. Eur. J. Pharm. Sci. 2018, 114, 103-113. [CrossRef] [PubMed]

37. Horak, D.; Babic, M.; Jendelová, P.; Herynek, V.; Trchová, M.; Pientka, Z.; Pollert, E.; Hájek, M.; Syková, E. D-mannose-modified iron oxide nanoparticles for stem cell labeling. Bioconjug. Chem. 2007, 18, 635-644. [CrossRef]

38. Bayramoglu, G.; Arica, Y. Adsorption of Cr(VI) onto PEI Immobilized Acrylate-Based Magnetic Beads: Isotherms, Kinetics and Thermodynamics Study. Chem. Eng. J. 2008, 139, 20-28. [CrossRef]

39. Gaspar, V.M.; Sousa, F.; Queiroz, J.A.; Correia, I.J. Formulation of chitosan-TPP-pDNA nanocapsules for gene therapy applications. Nanotechnology 2011, 22, 015101. [CrossRef]

40. Chithrani, B.D.; Chan, W.C. Elucidating the mechanism of cellular uptake and removal of protein-coated gold nanoparticles of different sizes and shapes. Nano Lett. 2007, 7, 1542-1550. [CrossRef]

41. Liu, S.; Guo, T. Polycation-Based Ternary Gene Delivery System. Curr. Drug Metab. 2015, 16, 152-165. [CrossRef] [PubMed]

42. Song, L.; Liang, X.; Yang, S.; Wang, N.; He, T.; Wang, Y.; Zhang, L.; Wu, Q.; Gong, C. Novel polyethyleneimine-R8-heparin nanogel for high-efficiency gene delivery in vitro and in vivo. Drug Deliv. 2018, 25, 122-131. [CrossRef] [PubMed]

43. Albuquerque, T.; Faria, R.; Sousa, Â.; Neves, A.R.; Queiroz, J.A.; Costa, D. Polymer-peptide ternary systems as a tool to improve the properties of plasmid DNA vectors in gene delivery. J. Mol. Liq. 2020, 309, 113157. [CrossRef]

44. López-García, J.; Lehocký, M.; Humpolíček, P.; Sáha, P. HaCaT Keratinocytes Response on Antimicrobial Atelocollagen Substrates: Extent of Cytotoxicity, Cell Viability and Proliferation. J. Funct. Biomater. 2014, 5, 43-57. [CrossRef] [PubMed]

45. Conniot, J.; Scomparin, A.; Peres, C.; Yeini, E.; Pozzi, S.; Matos, A.I.; Kleiner, R.; Moura, L.I.F.; Zupančič, E.; Viana, A.S.; et al. Immunization with mannosylated nanovaccines and inhibition of the immune-suppressing microenvironment sensitizes melanoma to immune checkpoint modulators. Nat. Nanotechnol 2019, 14, 891-901. [CrossRef]

46. Salatin, S.; Maleki Dizaj, S.; Yari Khosroushahi, A. Effect of the surface modification, size, and shape on cellular uptake of nanoparticles. Cell Biol. Int. 2015, 39, 881-890. [CrossRef]

47. Apostolopoulos, V.; Thalhammer, T.; Tzakos, A.G.; Stojanovska, L. Targeting antigens to dendritic cell receptors for vaccine development. J. Drug Deliv. 2013, 2013, 869718. [CrossRef]

48. Hossain, M.K.; Wall, K.A. Use of Dendritic Cell Receptors as Targets for Enhancing Anti-Cancer Immune Responses. Cancers 2019, 11, 418. [CrossRef]

49. Tang, C.K.; Sheng, K.C.; Apostolopoulos, V.; Pietersz, G.A. Protein/peptide and DNA vaccine delivery by targeting C-type lectin receptors. Expert Rev. Vaccines 2008, 7, 1005-1018. [CrossRef] [PubMed] 